\title{
Mapping Walkability. A subjective value theory approach.
}

\author{
Giovanna Fancello ${ }^{1 a}$, Tanja Congiu ${ }^{b}$, Alexis Tsoukiàs ${ }^{a}$. \\ a. LAMSADE, PSL University, CNRS, Paris Dauphine, Place du Maréchal de Lattre de Tassigny,75016, Paris, France \\ $b$. Department of Architecture, Design and Urban Planning, University of Sassari, Italy
}

Keywords: walkability; multi-criteria decision analysis; capability approach; preferences; multi-attribute value theory; decision maps.

\begin{abstract}
The analysis of urban walkability has been extensively explored in the last decades. Despite this growing attention, there is a lack of studies attentive on how citizens' values, individual abilities and urban environment favour or hinder the propensity to walk. Hence, there is a need to explore how preferences and values of citizens vary in space in order to design walkability policies able to improve the capability set of citizens. In this perspective, the design of spatial decision tools aimed to planning public policies for the development of walkable cities needs further investigation. We propose a Multiple Criteria Decision Analysis (MCDA) method aimed to elaborate walkability decision maps for different groups of citizens that reflect their capability to walk in the urban environment. We tested the method in the city of Alghero (Italy). First, we analysed walkability under a normative model named CAWS; then we made a survey with 358 participants in order to study the driving values that influence their choice to walk and finalised to build an evaluation model attentive to individual differences. Cluster analysis was employed to group citizens into 11 groups based on their sociodemographic characteristics and preferences on spatial criteria of walkability. Finally, by integrating the GIS with the MCDA we built a set of decision maps representative of the walkability of the different groups of citizens. Results highlight the importance of citizens' values for policy design, allow the interpersonal comparison among individuals and group preferences and give new suggestions for the formulation of walkability oriented urban policies. Moreover, the results confirm the usability of the general method as a decision support tool supporting the design of urban policies.
\end{abstract}

\footnotetext{
${ }^{1}$ Corresponding author

Present address: UMR 8504 Géographie-cités, CNRS, Université Paris 1 Panthéon-Sorbonne, Université Paris Diderot, EHESS, Campus Condorcet, 5, cours des Humanités, 93322 Aubervilliers cedex

e-mail: giovanna.fancello@parisgeo.cnrs.fr (Giovanna Fancello)
}

Funding: This project was supported by the PSL Research University with the Project MMAP "Measuring the maps".

Declarations of interest: none 


\section{Introduction}

Walkability is an important component in Urban Quality of Life (Rogers, Halstead, Gardner, \& Carlson, 2011; Talen, 2002), that allows to expand the possibilities of people to use and act in the city with reference to their needs and values. For this reason, it is one of the main aims of urban public policies in the last decades (Barton, Thompson, Burgess, \& Grant, 2015; Gehl, 2010; Oka \& Koohsari, 2020; Speck, 2018).

However, in the design of public policies it is not sufficient to claim that a walkable space is preferable to other spaces in order to support the policy making. In order to establish the precise set of actions which will improve walkability, we need to know - among other - how walkability is valued by different groups of citizens. Such analysis gives useful information for taking a public decision and for the design of a legitimated public policy (Meinard, 2017). Accordingly, beside their objective characteristics, citizens can be grouped on the basis of their subjective values. This allows to take into account the diversity of citizens in terms of preferences and needs (Ferretti, Pluchinotta, \& Tsoukiàs, 2019; Goodin, Moran, \& Rein, 2008; Simon, 1954, 1969).

The best known walkability analysis methods (Carr, Dunsiger, \& Marcus, 2010; Ewing \& Handy, 2009; Frank et al., 2010; Iacono, Krizek, \& El-Geneidy, 2010; Owen et al., 2007) present a normative-descriptive conceptualisation based on generalised rules applicable to a wide range of situations and individuals with no distinction for specific categories of citizens. Some models focus on specific groups of population (elderly, disabled people, children) and attempt to identify the factors that most affect their decision to walk (Bejleri, Steiner, Fischman, \& Schmucker, 2011; Buck et al., 2011; Garin et al., 2014; Guo \& Loo, 2013; Moura, Cambra, \& Gonçalves, 2017; Taleai \& Taheri Amiri, 2017; Towne et al., 2016), but the majority of them refer to the behaviour of a standard walker with no distinction among subjective preferences or needs, thus demanding for more personalisation.

Moreover, it is broadly acknowledged that the results of urban audits, used for the analysis of walkability, are affected by citizens' preferences which are very different from each other. Such a problem, usually considered a bias of the model, represents in our idea an opportunity for policy design. Policy design takes advantage from differences that offer an opportunity for innovative design (Ferretti et al., 2019). In other words, the diversity of citizens' preferences is a very useful information for building legitimated policies (Matti, 2004; Meinard, 2017).

Starting from these considerations, our focus in this paper is to improve the methodological background of walkability assessment tools and their effectiveness for policy design. We are interested in analysing citizens' values in space in order to design public policies attentive to individual diversities. Especially, we need to understand how different groups of citizens consider and react to the socio-spatial features that describe the walkability in the city. Hence the conditions and qualities of the urban environment that count in the decision to walk for different groups of individuals and their relative value are investigated. For this purpose, we propose a method attentive to individual diversity to be used as support tool for the design of policies in the city of Alghero (Italy) selected as case study. Operationally, this method yield to a definition of a set of decision maps (Malczewski, 1999; Malczewski \& Rinner, 2015) representative of the walkability of the different groups of citizens.

Despite the conventional economic well-being models (aimed to "count" commodities 
and based on normative prescriptions), our theoretical framework for the analysis of citizens' quality of life in cities is the Capability Approach (Nussbaum, 2005; Sen, 2009) based on individuals substantive freedoms (capabilities) to choose a "life one has reason to value" (Sen, 2009). Citizens' capabilities are valuable states of being that a person has effective access to (Sen, 2009). The development of capabilities depends from individual and environmental factors: (1) the ability, the person's internal power, detained but not necessarily exercised, to do and to be, and (2) the opportunity, the presence of external conditions which make the exercise of that power possible (Blečić, Cecchini, Congiu, Fancello, Talu, et al., 2015). Thus, the quality of life of citizens in a city is not given by the measure of distribution, density and distances of different opportunities in space. Rather, quality of life in cities is a multidimensional concept that depends on individual diversity and on the advantage that such urban opportunities give to citizens in order to develop capabilities.

Under such a perspective, citizens' values are fundamental for the process of choice of capabilities that can be developed into functionings, and therefore for the improvement of their quality of life in cities. Diversities among individuals (age, gender, health conditions, income, driving licence, place of residence, ...) can correspond to different values and to different possibilities "to do and to be" (Sen, 2009) in urban space.

The multi-attribute value theory family methods (Keeney \& Raiffa, 1976; von Winterfeldt \& Edwards, 1986) satisfies the demand of considering both the multidimensionality and the subjectivity of welfare. Thus, by using such family of methods, we intend to study values in order to group citizens primarily with respect to their preferences to do and to be in space, and secondarily with respect to their characteristics. Our hypothesis is that values functions are a good representation of each citizen driving values. Such an analysis consents to identify groups of citizens that would otherwise be invisible using a standard segmentation of the population (for example for ranges of ages).

Therefore, the main innovation of the proposed method is given by the focus on individual diversity for policy making. After a multiple criteria analysis of walkability, we propose to analyse the subjective character of well-being constituents (as it is the case with walkability) using the multi-attribute value theory methods. Finally, we explore both the multidimensional and subjective spatial variability of the walkability by grouping citizens (considering their needs and values) and by designing a set of decision maps representative of urban capabilities and limits. The final decision maps give useful information for policy designs focused on citizens' diversity. Thus, our main contribution to the literature on decision making for urban policies is a capability-oriented decision analysis method through which it is possible to establish a "customised" walkability model for a given urban context and population that highlight differences on urban capabilities.

According to these considerations, our research problem can be structured in three principal points:

(1) The definition of the criteria which describe walkability in our case study (Alghero).

Walkability is a multidimensional and complex concept which requires the use of multiple criteria decision analysis methods (MCDA) to be measured and evaluated. Despite the great production of walkability studies (Blečić et al. 2015a; Cervero \& Duncan 2003; Clifton et al. 2007; Forsyth 2015; Frank et al. 2006; Iacono et al. 2010; Lee \& Moudon 2006; Livi \& Clifton 2004; Porta \& Renne 2005; Saelens \& Handy 2008), there is no consensus about the criteria that must be considered in an analysis tool due to context embedded factors and to the diversity of city users. For this reason, we define a set of tailor-made criteria and attributes for the city of Alghero based on the idea of 
walkability as an urban capability (Blečić, Cecchini, \& Talu, 2013; Blečić, Congiu, Fancello, \& Trunfio, 2020).

(2) The analysis of the trade-offs between walkability criteria that reflect the preferences of decision makers here represented by the whole population of a city (residents, city users, tourists, ...). Above all, we are interested in recognising the differences between the values that distinct groups of citizens give to the walkability components in order to tailor policy interventions.

(3) The consideration of the "spatial component" in the evaluation process. The spatial representation resulting from an evaluation attentive to the diversities in urban space must be the result of the combination of the environmental features and their values for the citizens and not just a superposition of layers. The resulting maps (here named "decision maps") are representative of two components: 1) the spatial relations between the urban features and their specific location in the city and 2) the subjectivity of the walkability which takes into account the different values citizens gives to multiple walkability criteria. Decision maps consent to select among two alternatives because of their different spatial location, independently from their walkability assessment. Indeed, a change in the location of an alternative (here represented by the disparate possibilities to walk in the city) influences its final evaluation (Malczewski \& Rinner, 2015). This change is due to the multiple interconnected environmental features that need to be considered when spatial analysis is required (Malczewski \& Rinner, 2015). Decision maps help in showing the differences of capabilities among individuals when the city and its walkable space is assessed by them. It is the case when two different citizens consider the same street and assess its walkability differently due to their different capability sets.

In order to integrate the spatial component, we combine the MCDA method with GIS services (Malczewski, 1999; Malczewski \& Rinner, 2015). The GIS-MCDA model we proposed consents to 1) unveil specific spatial relations among the variables that describe a walkable environment and 2) catch the differences between the walkability of groups of citizens. Both these points give useful outputs for the policy design

The abovementioned three points are analysed in the following paragraphs. More precisely, in section 2 we articulate our theoretical background, then we argument our method in section 3, while in sections 4 to 7 we give operational details through the description of a case study. Conclusions are drawn in section 8 .

\section{Theoretical background}

\subsection{Analysis of walkability.}

Walkability is the potential of the built environment to encourage individuals walking. Among the multiple definition of walkability we claim it is a composite quality of urban space produced by the combination of several spatial factors related to the organisation and functionality of cities: the physical configuration of the urban fabric with its block structure and the connectivity of pathways; the presence and variety of activities intended as possible origin and destinations of trips; the quality of pedestrian accessibility which depends on the level of comfort, convenience, safety and pleasantness of footpaths, as well as on the attractivity and imageability of the traversed environment. Most walkability assessment methods are based on these features of the built environment (Blečić et al. 2015; Forsyth \& Krizek, 2010; Pikora et al., 2003; Saelens \& Handy, 2008). The importance assigned to each of them and the choice of measurement variables 
depend on the specific context of implementation which differ in geographical and cultural characteristics (for instance, safety and security issues highly affect the propensity to walk in cities with high levels of traffic accidents and crime) as well as for the amount of resources available for the study (time, economic funds, dataset accessible, ...).

Urban walkability is an operationalizable concept. As an indicator of how, where and to what extent urban environment is conducive to walk, it can be measured and spatialized. Most methods resort to composite indexes that combine in different ways the multiplicity of factors involved in the assessment. The main differences consist in the variables considered, in the algorithm used, data collection techniques adopted and outcomes.

In their review of existing pedestrian indices Maghelal \& Capp (2011) distinguished between (1) methods that quantify the amount of built-environment features into a single number that categorizes the physical environment as high, low, or moderately suitable to walk, and (2) methods such as audits, surveys and checklists that tend to measure the amount of built-environment features that support or hinder walking.

Recent advancements in spatial analysis, modelling and computing led to the development of several sophisticated walkability measurement methods and tools. Such tools are used by researchers, urban planners and practitioners in order to analyse and evaluate the walkability of the built environment, to represent the distribution in space of this quality and to explore its influence on people behaviour (Adlakha, 2017; Bader et al., 2015; Badland et al., 2013; Frank et al., 2006; Iacono et al., 2010; Peiravian, Derrible, \& Ijaz, 2014; Sundquist et al., 2011; Van Dyck et al., 2013; Yameqani \& Alesheikh, 2019). In fact, these methods are able to pinpoint how and to what extent urban environment encourages walking and makes urban opportunities reachable and available for use. The resulting knowledge can be used to inform urban policies and projects aiming to encourage active lifestyles and enhance people well-being. The decision of a person to walk is in fact influenced by a number of spatial and a-spatial factors (Alfonzo, 2005; Carlson et al., 2012; Forsyth et al., 2009; Handy, 1997). Urban planners and designers can act, first of all, on the spatial qualities making urban environment more conducive to walk for the majority of citizens. The walkability analytical methods we refer to in this study combine objectively measurable physical and functional characteristics of pathways (sidewalk presence and width, number of lanes, speed limits, ....) with urban design qualities affecting people's perception of the walking environment (imageability, enclosure, transparency) and other factors related to how pedestrians react to urban space (Ewing \& Handy, 2009; Moudon \& Lee, 2003). Moreover, walkability has a subjective value for each individual citizen. Various studies (Ewing \& Handy, 2009; Gebel, Bauman, Sugiyama, \& Owen, 2011; Zhou, He, Cai, Wang, \& Su, 2019) suggest that such subjectiveness results from two components:

- the subjective appreciation of what is relevant and important for a "space" to be walkable, this being independent from the socio-economic characteristics of the citizen;

- the subjective importance of how walkability of the surrounding space impacts the overall well-being of each citizen, the willingness and pleasure to walk being different and once again independent from the socio-economic characteristics of each citizen.

Indeed, the propensity of people to walk is influenced not exclusively by the presence and width of sidewalks or the distance to travel; it counts also if a path is pleasant and attractive to walk, if it is comfortable and perceived as safe and inclusive (Blečić et al., 2020; Forsyth, 2015; Talen, 2002). Therefore, we claim that convenience, comfort, safety, attractiveness and pleasantness represent essential spatial requirements that make 
walkability measures effective indicators of the quality of accessibility and thus to be included and evaluated in an accurate analysis of the distribution of the capability to walk in the city.

The complex nature of the walkability concept, which encompasses the abovementioned objective and subjective features of the built environment, leads most walkability measures to be formalised by composite indices that combine factors with different importance. The most used methods (Carr et al., 2010; Frank et al., 2010; Krizek, 2003; Saelens, Sallis, Black, \& Chen, 2003) resort to normative models in which the importance of factors involved in the decision to walk is assigned through a set of rules a priori based on an exogenous rationality, that is a rationality independent of the preferences of a specific decision maker (group of pedestrians) and thus applicable to a generality of situations.

However, there are many differences in the walking behaviour of people to be considered for making pedestrian friendly planning and design more effective. Individual characteristics, together with individual preferences influence the attitude of pedestrians in space. People with physical disabilities can be limited to access the city because of an unfriendly design of streets, in the same manner other citizens can modify their walking behaviour depending on the presence of specific qualities of urban space. This aspect lays even more emphasis on the analysis of the values citizens assign to walkability factors and their context-sensitive variability. The study of subjective values will permit thus to consider both citizens' needs (derived from people characteristics) and preferences in order to meet a more effective and inclusive design of the urban environment.

\subsection{The capability approach.}

As already mentioned, the Capability Approach (Sen, 1999, 2009) is our theoretical framework for the definition of walkability. The Capability Approach goes beyond the economic concept of well-being, stressing the importance of evaluating not primary goods or assets, but substantive freedoms (named capabilities) to choose a "life one has reason to value" (Sen, 2009). The concept of capability entails two components (Blečić et al. 2015a): the "ability" of an individual with respect to his personal characteristics, and the "opportunity" given by the socio-environmental context to freely access the set of resources and assets in terms of endowments. Thus, the capability set of a person depends both on individual and environmental factors (conditions and commodities) (Errore. L'origine riferimento non è stata trovata.). The aim of this approach is to enhance the freedom people have to choose their beings and doings (capability set) through the conversion of such commodities and conditions in advantage for their development. 


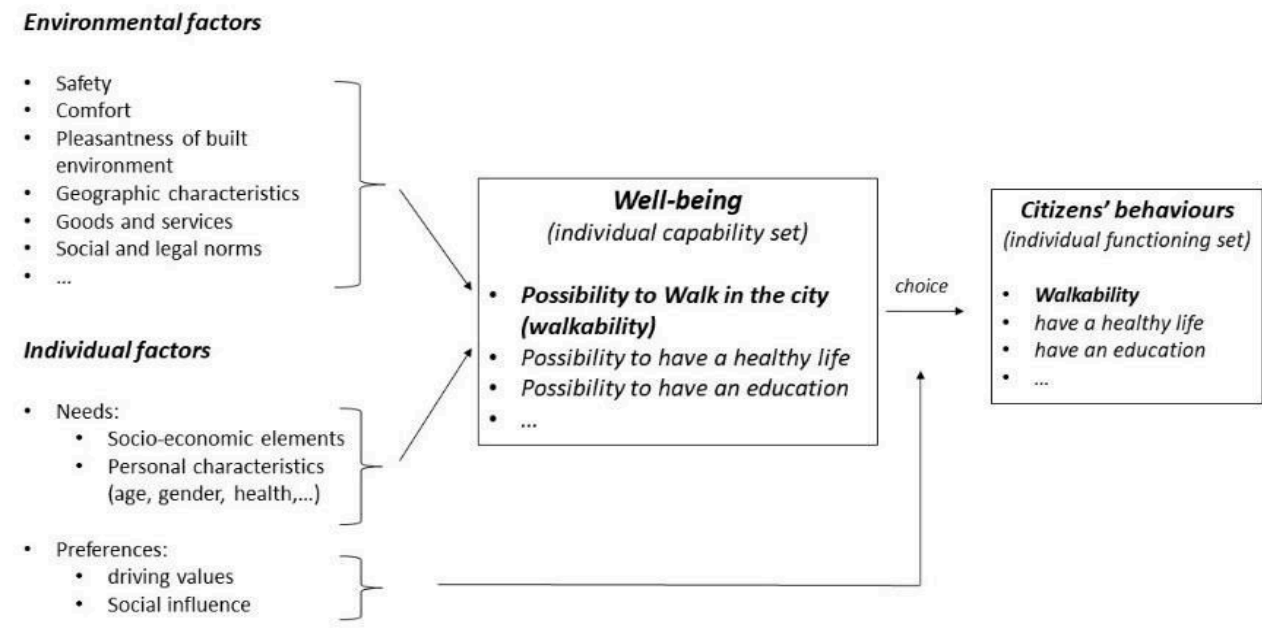

Figure 1: Determinants of well-being with specific attention to walkability (source: Author's elaboration from Robeyns (2017)

The notion of advantage deals with a person's real opportunity to use commodities compared to others (Sen, 2009). The advantage people take from the opportunity offered by the commodities is thus different for each individual. People can have different functionings (beings and doings) and a different capability set (combination of possible functionings) depending on socio-environmental factors. Likewise, the same person can convert the same commodity differently in different spaces, as well as two different persons in the same place may convert the same asset in different functionings. For all these reasons, the context plays a key role in the process of capability development.

As claimed by (Blečić, et al., 2015a; Blečić, Cecchini, \& Talu, 2013)there is a particular set of capabilities, named "urban capabilities", that is influenced by urban and territorial factors and the social context. Urban capabilities depend on urban and environmental opportunities intended as combinations of contextual factors that can be modified with a public policy. The walkability in the city is one of such urban capabilities (Blečić, Cecchini, Congiu, Fancello, \& Trunfio, 2015; Blečić et al., 2013).

According to these premises, we are interested to determine the values citizens give to urban and environmental factors that influence the walkability of places, and thus the urban capability set of citizens. These elements are the contextual factors that influence the choice to develop the urban capability to walk in the city.

The recognized multidimensional and subjective character of well-being leads us to move the analysis of walkability from a normative approach (used by the majority of walkability researches) to one attentive to the differences among citizens. For this reason, we resort to the multi-attribute value theory methods which allows analysing the complexity of the well-being constituents (as it is the case with walkability) by considering the preferences of citizens.

\subsection{Analysis of citizens' values.}

Evaluating environmental resources and cultural assets for which a real market does not exist is a well-known problem in literature (Dasgupta, 2001; Haab, McConnell, \& Bishop, 2002; Robinson, 2001). For environmental resources, such as urban and 
territorial opportunities, it means understanding the value of these commons and public goods even if it is not a monetary one (Robinson, 2001). Several methods help in the analysis of values of environmental resources considering revealed preferences or stated preferences that allow to define the demand curve of a hypothetical market (hedonic prices, travel cost, contingent and conjoint analysis) (Beinat, 1997; Ferretti, 2016). Although such methods are frequently used in environment economics in order to evaluate the impact of a project in space (Pearce, Atkinson, \& Mourato, 2006), they have been criticised due to the monetary vision of the space (Sen, 1995), which is not representative of the whole value of such resources and assets. They consider behaviours and preferences as explicable by normative models that look at citizens as rational consumers choosing to do something in the city thanks to an economic offer. Such a consumer is a standard one, acting in the city following convenience patterns. These methods are not able to inspect subjective values given by individuals to the city. With reference to such critiques we note Sen's work (Sen, 1995), about environmental evaluation and social choice, in which he claims the necessity to consider the individual not just as an operator in a market, but as a citizen that judges alternatives from a social perspective, including (among others) his well-being. This reminds the necessity to learn the subjective values of citizens without any a-priori hypothesis as far as the rationality of their behaviour is concerned.

In decision theory there are numerous studies (see the review given by Smeulders et al. 2019) that build value functions starting from the information gathered by the choices of one or more decision makers. This approach is developed especially by studies interested in multiple criteria decision analysis (Belton \& Stewart, 2002; Bouyssou et al., 2000). Among such methods we focus on the multi-attribute value theory approach (Keeney \& Raiffa, 1976; von Winterfeldt \& Edwards, 1986) which consents to evaluate alternatives under multiple criteria using subjective values. Multi-attribute value theory (MAVT) is a method representing preferences through value functions, but also a way to measure preferences in terms of their intensities (how much A is better than B?). Since MAVT measures preferences using the same unit of measure (i.e. values), it allows commensurability among individuals. If we know the value functions of two individuals $x$ and $y$ then we are allowed to formulate sentences of the type: alternative $a$ will increase the value for $x$ twice more than for $y$. It allows to compare citizens with respect to their values and thus, to group them when these (the value functions) are "similar". The valuebased information helps to design and plan public policies with respect to what citizens and stakeholders want. Moreover, this decision analytic methodology consents to measure individual preferences in non-monetary terms, fostering its use for the analysis of environmental values (Ananda \& Herath, 2003; Beinat, 1997; Ferretti, Bottero, \& Mondini, 2014; Martin, Wise Bender, Shields, Bender, \& Shields, 2000).

We propose to learn value functions with holistic (or indirect) methods (Beinat, 1997), that are based on overall value judgements of multi-attribute profiles and a successive estimation of the marginal value functions with fitting techniques. These methods offer a representation of the set of preferences and values that the decision maker uses in order to make a choice and consent to estimate the total value of an alternative by summing the marginal values of attributes determined by their value function.

Moreover, since we cannot design policies that meet the preferences of every single citizen, we group people with similar preferences and needs and propose policies for those groups. With this purpose, we resort to cluster analysis which allows to group individuals with similar characteristics, simplifying the structure of the community. This 
will consent the policy maker to have useful information for choosing between policy alternatives framed considering one or more groups of citizens' preferences. Thus, rather than define a method able to design a policy preferred by all the citizens, our final aim is to offer to policy makers a policy analytics method (Marchi, Lucertini, \& Tsoukiàs, 2016) supporting the design of policies legitimated by citizens (Meinard, 2017). The purpose is not to assess the value of any alternative for all citizens together, but only for the ones sharing the "same" (or "very similar") value functions. In other terms we want to know that citizens belonging to cluster $\Theta$ are characterized by value functions for which a given alternative is valued $\mathrm{K}$. If we are able to cluster the citizens through their value functions, we can now make sentences of the type: alternative $a$ will be twice more appreciated by the cluster $\mathrm{X}$ with respect to cluster $\mathrm{Y}$ and others similar, allowing to design policies (or alternatives) targeting specific clusters of citizens.

This is a specificity of our model that takes advantage from citizens' differences that we claim offer opportunities for innovative design. For this reason, we are not interested to explore the total value of an alternative, rather to shed light the difference of values that an alternative can have considering different groups of citizens and different locations.

\subsection{Spatial MCDA and GIS services.}

The urban space is one of the elements that we consider as determinant in the analysis of walkability and as such requiring the use of specific tools that integrate Multiple Criteria Decision Analysis (MCDA) with Geographic information Systems (GIS).

The integration of MCDA and GIS increased in the last 25 years (Malczewski, 2007; Malczewski \& Rinner, 2015) revealing the opportunities for the study of spatial decision problems offered by the combined use of these fields of research. A GIS is a set of tools and systems useful to analyse geographical data for decision problems, while the MCDA methods and techniques allow to structure decision problems and evaluate alternatives with respect to decision maker's preferences. According with Malczewski and Rinner (2015), a spatial MCDA method integrated with GIS services will consent to analyse geographical data and to consider decision maker's preferences and needs for the evaluation of alternatives (defined in a spatially referenced data).

GIS technology permits to overlay the information that satisfy the criteria of a decision maker. However, when some conflicting preferences are present, GIS tools are not able to provide useful support (Malczewski \& Rinner, 2015). A GIS-MCDA model goes beyond this problem and allows to combine spatial data and decision maker's preferences into an output map, named "decision map". We define a decision map as a synthesis of multiple information in space which prove to be useful, meaningful, legitimated and legitimating (Meinard, 2017) the definition of innovative public policies. According to these premises, a GIS-MCDA system helps to develop new alternatives in a constructive and innovative way by considering the preferences of citizens. More precisely, a GIS-MCDA system considers the preferences of the decision maker with respect to the spatial constituents (both position and characteristics) and builds decision maps aiding in the design of public policies.

The literature and case studies on GIS-MCDA (named also Multiple Criteria Spatial Decision Support System) in the lasts 10 years are very productive, thanks both to the recognition of decision analysis as essential for the GIS, and to the increase of low-cost and easy MCDA software. The reader interested in a literature review can see the works 
of Chakhar and Martel (2003); Lidouh (2013); Malczewski(2007); Malczewski and Rinner (2015). Malczewski \& Rinner (2015) discerns among three different approaches used in literature for the integration of GIS-MCDA methods: (1) conventional approaches, that use MCDA models for spatial problems as site selection or land use analysis in spatial decision making; (2) spatially explicit MCDAs, that represent models influenced by the spatial location of the alternatives, geographically represented; and (3) spatial multi-objective (multicriteria) optimization aimed to find the best solution to spatial decision problems (transportation, location allocation, vehicle routing,...).

In this paper we combine multi-attribute value theory methods (MAVT) with GIS in a conventional approach in order to yield a spatially explicit multiple criteria model that supports the analysis of urban walkability considering people's preferences of space. We assume a spatial homogeneity of the decision maker's preferences given the value functions of one citizen (or group of citizens) within a study area. Finally, MCDA and GIS services are used in a spatial decision problem in order to build decision maps that represent the driving values of citizens walking in the city. We are conscious that our method, using a single value function for the study area (for one citizen), ignores the possibility that the form of the function may depend on the local context (i.e. location of the alternatives). This will be the objective of our future research.

Even if we use the same model for the whole study area (without differences in space), our model can be defined as spatially dependent since the evaluation of the walkability of the paths depends on the location of the alternatives. This means that two paths with identical characteristics but located in different cities or areas will be assessed differently. In order to evaluate this spatial dependence, we include among the attributes of walkability a set of features independent and separable from the path's attributes and dependent on the context characteristics: namely the architectural and the environmental quality of the landscape. With regard to such characteristics, our model can be considered as a conventional one.

Finally, the spatialization of our model is also due to the geographical localization of the alternatives (all the possible walkable paths in a city) and to the spatialization of the results of the MCDA evaluation with a raster map that considers citizens' values.

\section{Method}

In order to define groups of people with similar preferences and values referred to the walkability of urban space we propose a multiple criteria analysis method that combines choice experiments (Hanley, Mourato, \& Wright, 2002) with cluster analysis (L. Kaufman \& Rousseeuw, 2005), preference learning (Fürnkranz \& Hüllermeier, 2010) and GIS services. This method aids to estimate values that describe how the built environment is conducive to walk for different groups of citizens. Such groups of citizens differ from the classical socioeconomic statistical classes. In fact, they are determined considering the driving values that influence the choice to walk in the city for every citizen together with socioeconomic characteristics.

The proposed method is composed of different phases as outlined in Figure 2.

1. Data collection of two types of information: (1) individual data (declared preferences, socioeconomic profile, health status, sports behaviours, walking behaviours) collected with an ad-hoc survey; (2) data from the context of study (the set of attributes chosen to describe the street network). 
2. Walkability analysis: definition of criteria and spatial analysis of the street network attributes considering the study context.

\section{Analysis of citizens' values:}

- Analysis of preferences aimed to estimate the value functions of citizens by their judgments.

- Classification of preferences:

- The selection of relevant factors for personalization subphase allows to simplify the model by removing the socioeconomic factors that, even if considered important, do not change the final classification. It implies a first cluster analysis of the value functions of respondents and a rough set analysis.

- The main Cluster analysis sub-phase detects citizens with similar preferences and similar socioeconomic characteristics and determine homogeneous group of citizens.

- The Cross check of the results in order to verify and improve results with the support of a focus group composed by citizens interviewed and representative of the cluster identified in the analysis of data and by mobility and urban planner experts.

4. Spatial MCDA consists on mapping citizens' values in space. It is an experimental phase which aims to synthesize citizens' values in space by combining the CAWS method, the GIS tools and the results of citizens' value analysis. This phase produces a set of decision maps representative of the freedom to choose to walk in the city for different groups of citizens.

5. Recommendation. Final remarks and information directed to the policy makers. This phase can be coupled with the comparison of results with the value functions of a political delegate.

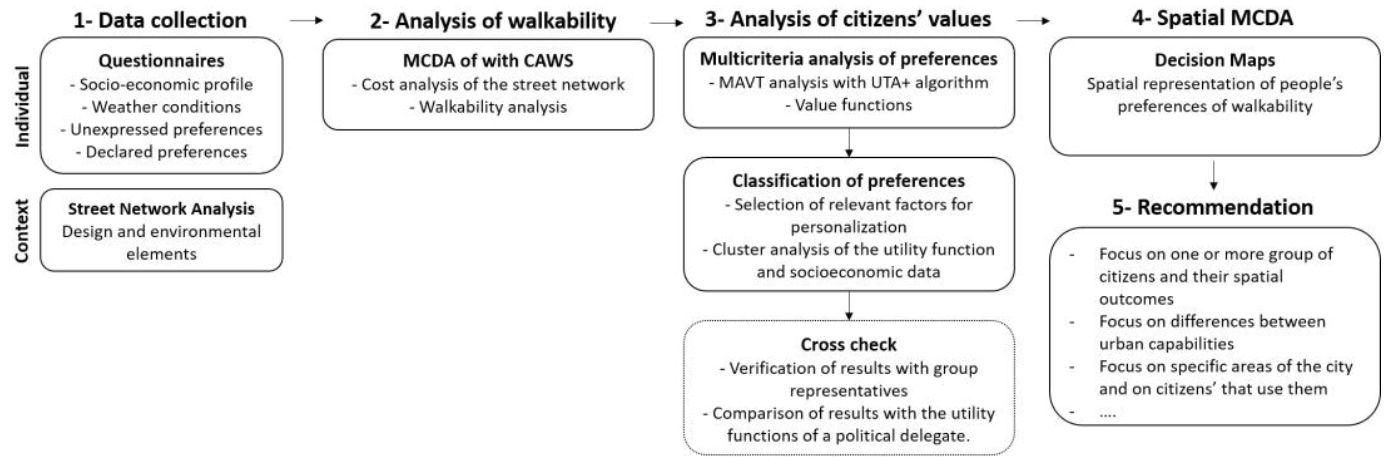

Figure 2: Multiple Criteria Analysis Method

\section{Data Collection}

As an empirical application of the methodology presented above, we applied the evaluation method in the city of Alghero, a coastal town of about 40.000 inhabitants located in North-West Sardinia (Italy).

We built a survey in order to study the driving values that influence the choice of citizens to walk in the city. In our experiment we suppose that exist citizens who value in a similar way the urban space (and what they can do in urban space) thanks to the spatial components. Convenience sampling was used to select participants of the study. Convenience sampling is a method of collecting data by taking samples that are conveniently available to participate in study that is widely used in walkability literature 
with the purpose to explore people's preferences (Carr et al., 2010; Carr, Dunsiger, \& Marcus, 2011; Chan, Schwanen, \& Banister, 2019; Rohrer, Pierce, \& Denison, 2004; Zandieh, Flacke, Martinez, Jones, \& van Maarseveen, 2017). We chose a sample regardless of demographic difference because we are interested on the difference among preferences and preferences are not only linked on demographic aspect. Moreover, convenience sampling consents us to reach a high number of participants with low time and resource consuming.

We learned walkability preferences through a choice experiment by using as possible scenario a set of walkability paths scattered throughout the Alghero study area (Arnberger \& Eder, 2011; Guo \& Loo, 2013). The questions proposed to the interviewed reproduced the choice process that citizens make when walking in the city (link to the questionnaire).

The questionnaire was structured into two different sections: the first one containing personal information of the interviewed (demographic and socioeconomic profile, living habits and attitudes towards walking and active transportations) and the circumstances of the survey (location and weather conditions with the latter proving to affect the propensity of people to walk); the second part dedicated to inquiry people preferences with respect to the walkability of streets: it encompassed unexpressed preferences collected through the judgment on 10 street photos and declared preferences with respect to quality attributes of the paths defined according to the literature (Forsyth, 2015; Gardner, Johnson, Buchan, \& Pharoah, 1996). We arranged four different questionnaires which differ for the selection of the streets to be evaluated. In total 40 streets (colour dots

Figure 3) were selected considering both location and walkability features and their image, from Google Street View, inserted in the questionnaire.

We then started investigating which path the interviewed would prefer and choose to walk to a particular destination in the city. Our final aim was to order the streets considering citizens' preferences. For this purpose, we asked citizens to judge the walkability of a list of 10 streets, represented by pictures, in a Likert-type scale from 0 to 3. The reader should note that for this work we did not really used the "Likert" property of these scales which were considered as just ordinal scales (with 4 values or grades). The reason is that we actually constructed upon these scales value functions (an interval scale of differences of preferences among the possible grades). WE choose to use a Likert-scale in order to facilitate the responses of interviewed. For each street picture the question posed to the interviewed was: "Do you think this road is suitable for walking?" (Give a rating from 0 to 3, with 0 corresponding to the negative answer "not suitable for walking at all: it is unsafe, unpleasant, uncomfortable, inconvenient"; 1 corresponding to: "low suitable for walking"; 2 corresponding to: "Suitable enough for walking (but needs some transformation)"; and 3 corresponding to the judgment "this street is perfect for walking"). This procedure allowed us to order the alternatives (i.e. streets) from the best to the worst one, avoiding to demand the interviewed to do this, and to build value functions representing such ordinal scales.

Interviews to residents and city users of the city of Alghero were made during the month of June 2017 with the help of a group of students. The sample locations were scattered throughout the Alghero study area and collected both in strategical places of the city (civic market, postal office, schools, gardens, ...) and by distributing the questionnaires on-line. We tried to interview different categories of people in order to understand the trade-off of urban values between groups of people as we can see in the socioeconomic analysis of the sample (see paragraph 4.1). 


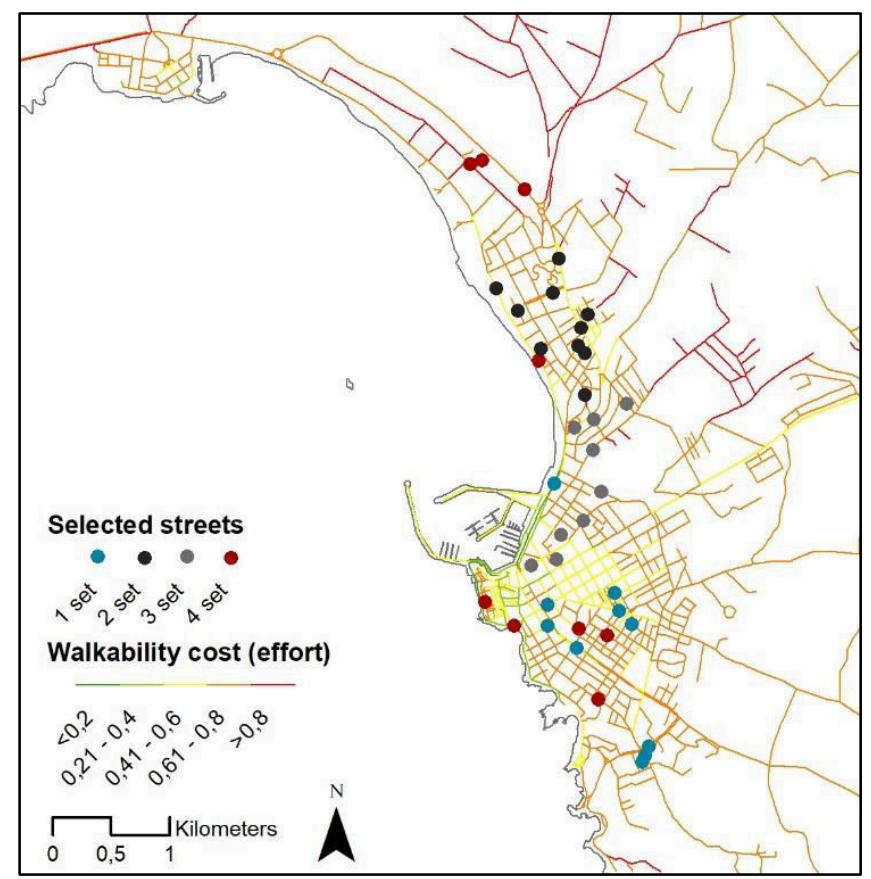

Figure 3: Localization of street used in questionnaires

\subsection{Study Participants}

We collected a total of 358 interviews in which individuals expressed their own preferences with respect to how Alghero roads are conducive to walk. The majority of participants were female $(59,78 \%)$, with an age between 10 and 80 years old (mean age of 34 years $(\mathrm{SD}=13,9)$. An important part of respondents are students $(34,08 \%)$, followed by employees of government departments, agencies, education and public health facilities $(20,11 \%)$ and private sector $(14,80 \%)$. More than two-thirds reported to play sports regularly and the majority used to walk for transportation or for recreation within their neighbourhoods ( $96 \%$ and $85 \%$ respectively). Finally, the majority of respondents (89\%) have not health problems limiting walking, while around the $8 \%$ have few health problems for walk (heart failure, respiratory problem, ...), and around the $2 \%$ have severe mobility problems.

We are conscious that the composition of the sample is a limit because a significant portion of the participants are students $(34 \%)$. We invite the reader to take into consideration that this is an experimental application of the model. In case of a real policy problem a sample statistically significant should be constructed.

Table 1: Demographic characteristics of the sample (\%)

\begin{tabular}{|c|c|c|}
\hline \multirow{2}{*}{ Gender } & Female & 59,7 \\
\hline & Male & 40,2 \\
\hline \multirow{8}{*}{ Age group } & $10-18$ & 1,6 \\
\hline & $19-29$ & 49,4 \\
\hline & $30-39$ & 19,5 \\
\hline & $40-49$ & 10,3 \\
\hline & $50-59$ & 11,1 \\
\hline & $60-69$ & 6,4 \\
\hline & $70-79$ & 1,1 \\
\hline & $>80$ & 0,2 \\
\hline Health & no & 89 \\
\hline
\end{tabular}

\begin{tabular}{lrr}
\hline & students & 34,1 \\
& state employees & 20,1 \\
Employment & professionals & 7,8 \\
& private sector worker & 6,9 \\
\cline { 2 - 3 } & retailed & 1,1 \\
\hline Place of & unemployed & 3,1 \\
residence & other employment & 26,82 \\
\hline Lifestyle \& & Alghero & 88,2 \\
walk habits & outside Alghero & 11,7 \\
\hline
\end{tabular}




\begin{tabular}{rr} 
some & 8,1 \\
\hline serious & 1,9 \\
\hline
\end{tabular}

\section{Analysis of Walkability}

In line with the methodological premises, in order to analyse the urban walkability in the city of Alghero, we chose to use the Capability Wise Walkability Score (CAWS) method developed by Blečić et al. (2015a; 2015b). We could have used another model for the measurement of walkability in order to develop our methodological framework and demonstrate the need to gather the diversity among citizens. However, we chose and suggested to use CAWS for the analysis of walkability because of its coherence with the capability approach framework. Moreover, CAWS performs a micro-level analysis of the urban determinants of walkability that consents to assess and spatially represent the distribution of walkability in cities. Last but not least, CAWS allows to personalise the trade-offs among walkability variables; this characteristic consents to easily customize the decision analysis model for each group of citizen and to explore the different outcomes.

CAWS conceives walkability as an important urban capability to achieve and enhance (Blečić et al., 2013). A walkable environment contributes to enhance people well-being: it makes easier to access and use urban services, activities and public space of everyday life; it supports people to be independent, to interact and to lead physically active lifestyle. For these reasons we consider walkability an enabling urban condition which can support effectively people in the expression of their human capabilities (Blečić, Cecchini, et al., 2020; Blečić et al., 2013) .

The theoretical assumption of the model is that the spatial system, intended as the combination of environmental determinants to walk, influences people behaviours and their decision to walk, thus giving rise to a context-specific distribution of possibilities to walk.

Operationally, CAWS model considers three components of the built environment (number and variety of destinations, distance to destinations and quality of pedestrian accessibility) whose combination leads to a final walkability score (WS) for each point in space. The resulting WS expresses the potential of a person located in a specific point in space to reach by foot a set of urban destinations important for daily life, and the elaborated walkability maps offer an analytic representation of the spatial distribution of the "pedestrian mobility capital" of population, giving useful information for policy interventions and spatial improvements.

More specifically, the CAWS evaluation model uses:

- A rich collection of urban activities bundled into three different opportunity sets: retail and commerce, leisure, urban services to be considered as possible destinations. This subdivision is done considering these three categories as basic urban facilities representative of substantive urban capabilities (e.g. the possibility to study, the possibility to have an healthy life, ...) (Nussbaum, 2005; Sen, 2009).

- A comprehensive graph representation of the street network to determine spatial distances among places and destinations.

- A detailed characterization of every edge of the street network graph through 17 attributes describing the physical and functional features of the streets and its surrounding environment considered relevant for making the urban space attractive, safe, pleasant and comfortable for pedestrians. 
Table 2. shows the attributes, their trade-offs defined by the CAWS model and the variables associated to each street edge. CAWS (Blečić, et al. (2015b; 2015)) defines trade-offs in a normative way by asking to a focus group composed by urban experts (urban designers, transport experts, policy makers) to define the importance of the attributes.

In this study, we started using the trade-offs of the original CAWS model, then we built personalized trade-offs for different groups of citizens and apply them in order to build decision maps attentive to citizen's differences.

Table 2: Street network attributes considered in CAWS model. Blečić et al. (2015a; 2015b).

\begin{tabular}{|c|c|c|}
\hline Attributes $(\alpha)$ & $\begin{array}{l}\text { Trade-off } \\
\text { (CAWS } \\
\text { model) }\end{array}$ & Parameters \\
\hline Width of sidewalk (accessible) & $2 / 30$ & $\begin{array}{l}\text { wide }(0.8) \text {; comfortable }(0.7) \text {; minimum }(0.5) \text {; inadequate }(0.3) \text {; } \\
\text { lacking }(0.1)\end{array}$ \\
\hline Cyclability & $2 / 30$ & $\begin{array}{l}\text { exclusive lane }(0.8) \text {; off-road lane }(0.5) \text {; on.road lane }(0.3) \text {; not } \\
\text { possible/prohibited }(0.1)\end{array}$ \\
\hline Car speed limit & $2 / 30$ & $\begin{array}{l}\text { pedestrian way }(0.8) ; 20 \mathrm{Km} / \mathrm{h}(0.7) ; 30 \mathrm{Km} / \mathrm{h}(0.5) ; 50 \mathrm{Km} / \mathrm{h} \\
(0.3) ; 70 \mathrm{Km} / \mathrm{h}(0.1)\end{array}$ \\
\hline Width of the roadway & $1 / 30$ & $\begin{array}{l}\text { pedestrian way }(0.8) \text {; one car lane }(0.6) ; 2 \text { car lanes }(0.5) ; 3 \text { car } \\
\text { lanes }(0.3) ;>3 \text { car lane }(0.1)\end{array}$ \\
\hline One way street & $1 / 30$ & pedestrian way $(0.8)$; yes $(0.5)$; no $(0.1)$ \\
\hline On-street parking & $1 / 30$ & prohibited parking $(0.8)$; permitted $(0.5)$; illegal parking $(0.1)$ \\
\hline $\begin{array}{l}\text { Paving (quality and degree of } \\
\text { maintenance) }\end{array}$ & $2 / 30$ & fine (0.8); cheap (0.5); bumpy $(0.1)$ \\
\hline Path slope & $2 / 30$ & smooth $(0.8) ;$ light $(0.5) ;$ rise $(0.1)$ \\
\hline Lighting & $1 / 16$ & excellent $(0.8)$; good $(0.6)$; inadequate $(0.3)$; lacking $(0.1)$ \\
\hline Shelter and shade & $1 / 16$ & strong $(0.8)$; weak $(0.5)$; lacking $(0.1)$ \\
\hline $\begin{array}{l}\text { Separation of pedestrian route from } \\
\text { car roadway }\end{array}$ & $2 / 30$ & marked/strong (0.8); weak (0.5); lacking (0.1) \\
\hline Opportunity to sit & $1 / 16$ & extended $(0.8)$; thin $(0.5)$; lacking $(0.1)$ \\
\hline Urban texture & $1 / 16$ & $\begin{array}{l}\text { dense }(0.8) \text {; park or green space }(0.6) \text {; low density }(0.4) \text {; } \\
\text { undeveloped land }(0.1)\end{array}$ \\
\hline Frequency of services and activities & $1 / 16$ & $\begin{array}{l}\text { abundant }(0.8) \text {; somewhat }(0.6) \text {; rare }(0.3) \text {; no services/activities } \\
(0.1)\end{array}$ \\
\hline $\begin{array}{l}\text { Transparency and permeability of } \\
\text { the public-private space }\end{array}$ & $1 / 16$ & integrated (0.8); filtered (0.5); separated $(0.1)$ \\
\hline $\begin{array}{l}\text { Interest from an environmental } \\
\text { point of view }\end{array}$ & $1 / 16$ & $\begin{array}{l}\text { prevalence of pleasant elements }(0.8) \text {; presence of a few pleasant } \\
\text { elements }(0.6) \text {; lack of pleasant or disturbance elements }(0.4) \text {; } \\
\text { presence of a few disturbance elements }(0.2) \text {; prevalence of } \\
\text { disturbance elements }(0.1)\end{array}$ \\
\hline $\begin{array}{l}\text { Interest from an architectural and } \\
\text { urban viewpoint }\end{array}$ & $1 / 16$ & $\begin{array}{l}\text { prevalence of pleasant elements }(0.8) \text {; presence of a few pleasant } \\
\text { elements }(0.6) \text {; lack of pleasant or disturbance elements }(0.4) \text {; } \\
\text { presence of a few disturbance elements }(0.2) \text {; prevalence of } \\
\text { disturbance elements }(0.1)\end{array}$ \\
\hline
\end{tabular}

According to the CAWS model, we consider the street network as composed by a set of points $Y$ offering opportunities in the city (i.e. green facilities, services, commerce):

$$
Y=\left\{y_{1} \cdots y_{i} \cdots y_{n}\right\}
$$

In the following we will use indices $i, j$ to indicate different points (departures or arrivals of any possible walk). We thus get a set of $\operatorname{arcs} X$ connecting the set of points $Y$ :

$$
X=\left\{x_{i j}: \exists y_{i}, y_{j} \in Y \wedge C\left(y_{i}, y_{j}\right)\right\}
$$


Where $C \subseteq Y \times Y$ is a binary relation representing the existence of a connection between two nodes. Finally, we have a set of paths $P$ that are a set of arcs connecting two nodes. The value function (for citizen $\chi$ ) $\varpi_{\chi}$ for any path is a function aggregating the values of all arcs being part of the path function of the arcs. Given a path $p_{l} \in P$ we have:

$$
\varpi_{\chi}\left(p_{l}\right)=\Psi_{x_{i j} \in p_{l}}\left(v_{\chi}\left(x_{i j}\right)\right)
$$

Where $v_{\chi}$ represents the value function for single arcs for citizen $\chi$. If we accept that the value of each path is independent from the value of any subset of arcs, then we can use an additive function such that:

$$
\varpi_{\chi}\left(p_{l}\right)=\sum_{x_{i j} \in p_{l}} v_{\chi}\left(x_{i j}\right)
$$

Then, we denote by $D\left(y_{i}\right)$ the set of all the destinations reachable from node $y_{i}$. We use the variable $z$ for all such destinations and we denote as $u_{z}$ the utility received by visiting $z$ and by $c_{y z}$ the cost afforded in order to reach $z$ (from $y$ ). We finally use the variable $n_{z}$ in order to indicate the number of times the destination $z$ can be reached. We define as walkability score of any node $y_{i} \in Y$ the solution of the following optimization problem:

$$
\text { Walkability Score }(y)=\max \left(\sum_{z \in D_{(y)}} u(z) n_{z}^{p}\right)^{\frac{1}{\rho}}
$$

Subject to

$$
\sum_{z \in D_{(y)}} c_{y z} n_{z} \leq K
$$

Where $K$ is the available budget for walking to the various destinations and $\rho$ is a parameter representing the constant elasticity of substitution among destinations.

Considering that walking through an arc is evaluated by any user as an activity possibly rewarding, we consider a set of "rewarding attributes" $A=\left\{\alpha_{1}, \cdots, \alpha_{m}\right\}$ (Table 2), we denote the generic attribute as $\alpha_{k}$ and we establish the trade-offs among such attributes as $w_{k}$ with

$$
\sum_{k=1}^{m} w_{k}=1
$$

According to equation 3 , as specified in equation 4 , given a path $p_{y z}$ the cost of using the path will be thus defined as 


$$
c_{(y z)}=\sum_{x_{i j} \in p_{y z}} l_{x_{i j}}\left[1-\left(\sum_{k=1}^{m} w_{k}\left(v_{k}\left(\alpha_{k}\left(x_{i j}\right)\right)\right)^{\rho}\right)^{\frac{1}{\rho}}\right]+c_{0}
$$

Where $c_{0}$ is a fixed cost, $l_{x_{i j}}$ is the length of arc $x_{i j}, w_{k}$ is the weight of the attribute $\alpha_{k}$, $v_{k}$ is the value of the arc on the attribute $\alpha_{k}$ and $\rho$ is a parameter representing the elasticity of substitution among attributes.

The variable part of this expression yields unit cost of 1 when all attributes are at their minimum (i.e. 0 ) and approaches 0 when attributes approach the maximum (i.e. 1).

In the CAWS algorithm all combined attributes have a specific importance (trade-off, see Table 2) assigned by rules defined according to the literature and advice of experts in urban planning and transport fields. In this sense it can be classified as a normative model of decision making based on an exogenous rationality and independent of pedestrians' preferences.

Finally, using a path-finding algorithm over graphs, the model searches for all the destinations reachable by foot from each node in the graph, correcting the plain geometric streets distances for walkability cost. More precisely, among many alternative paths from an origin to a destination in the street network, the model plugs the less costly (i.e. the one with the best combination of length and quality). Next, considering both the number of destinations and their walkability-corrected distances, the model assigns a walkability score (WS) to each node of the graph. These scores are then interpolated to finally obtain a map of distribution of capability-wise walkability in space. In Figure 4 we can see the maps of street costs and the maps of walkability generated by the Walkability Explorer software by using the CAWS model for the city of Alghero (Italy). The reader interested can found the map here. For more information on CAWS evaluation model see Blečić et al. (2015a; 2015b).

The resulting Walkability Score of each point in space, rather than indicating how much a specific place is in itself walkable, given its intrinsic place-specific characteristics (as in the majority of walkability evaluation methods and indicators), reflects where to and how a person can walk starting from that place; in other words, what is the walkability that a specific location is endowed with.

This conceptualization of walkability provides the link with the capability approach and specifically with urban capabilities, for it takes into account both the opportunity sets (i.e. the number and variety of possible attractive destinations) distributed in urban space, as well as the quality of urban environment (specifically in terms of how it is conducive to walk) which is relevant for the relation people may entertain with their living environment.

However, in using this model we do not take into account the subjective value that different citizens may attribute to the arcs as a result of their personal values. In the following section we take care of this issue. 


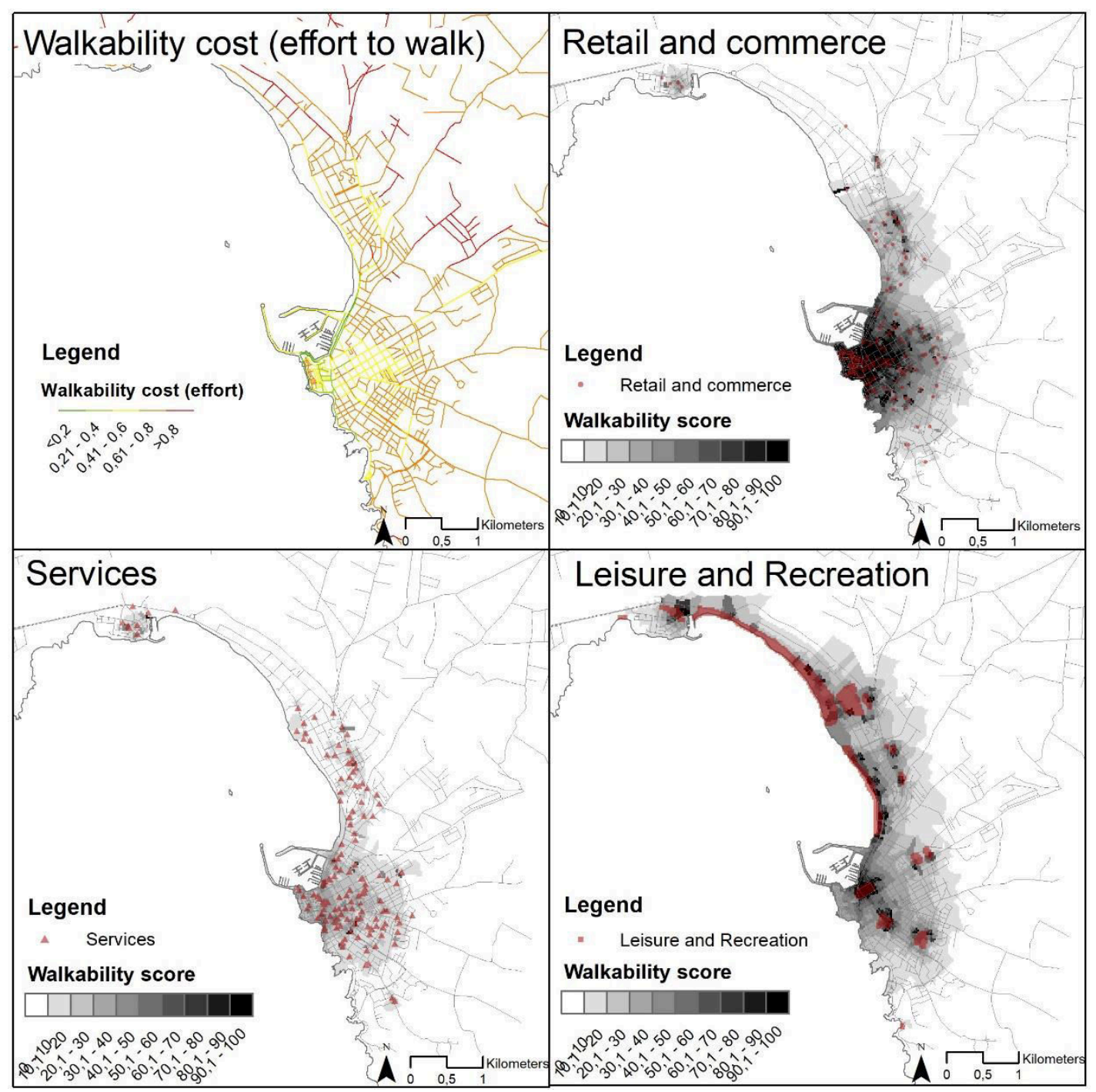

Figure 4: Street Cost and Walkability score for different types of opportunities (Services, Retail and Commerce, Leisure and Recreation) in a normative model.

\section{Analysis of citizens' values}

\subsection{Multiple Criteria Analysis of preferences}

This phase (see Figure 2) aims to define citizens' value functions with respect to the attributes that describe the street environment. Each citizen is considered as a decision maker choosing the best walkable areas in Alghero city with respect to his environmental preferences and needs. Among the possible walkable areas, we are interested in inspecting such areas that fit the needs and values of walkers: what helshe can freely choose to access by walking being influenced by the urban environment and histher personal characteristics. The analysis of space can be then intended as a multiple criteria decision-making problem that aims to rank a set of finite alternatives, i.e. all the possible streets offered by the city and valued as walkable by the individuals.

We learned preferences through a choice experiment (Arnberger \& Eder, 2011; Guo \& Loo, 2013) (see paragraph 4) and we chose to analyse results with the Additive Utility Functions (UTA) family of methods (Jacquet-Lagreze \& Siskos, 1982; Keeney \& Raiffa, 
1976). UTA is a family of multi-criteria decision analysis methods aimed to evaluate alternatives thanks to a set of value functions adopting the preference disaggregation principle: obtain global preference statements upon a set of choice examples and then infer the value functions that better fit such statements. UTA was originally proposed by Jacquet-Lagreze \& Siskos (1982) and then developed in different forms (Greco, Kadziński, Mousseau, \& Słowiński, 2012; Kadziński, Greco, \& Słowiński, 2012; Siskos, Grigoroudis, \& Matsatsinis, 2005). The method builds a set of additive value functions from a ranking on a reference set $A$ given by the decision maker. It uses linear programming in order to estimate the family of utility functions with the minimum possible error and to compute the optimal set of functions as consistent as possible with the given preferences. In synthesis, UTA method disaggregates the preferences of the decision maker but finally allows a complete evaluation of the problem. Such a method assumes the commensurability among citizens' values and allows to compare and group similar values, a known problem that affects the public policies having to deal with multiple stakeholders.

The criteria aggregation model in UTA is an additive value function (Jacquet-Lagreze \& Siskos, 1982):

$$
u(x)=\sum_{i=1}^{n} p_{i} u_{i}(x)
$$

where $u_{i}, i=1,2, \ldots, n$ are non-decreasing real valued functions, named marginal value or utility functions, which are normalized between 0 and 1 , and $p_{i}$ represents the trade-offs among the criteria that define $u$.

This method was used in decision aiding for different multiple criteria problems and in the environmental field for the evaluation of projects (Greco et al., 2012; Kadziński et al., 2012; Siskos, 1983; Siskos \& Assimakopoulos, 1989). Here we propose to use this family of methods in order to analyse citizens' values in a way that represents citizens' preferences to walk.

According to this method, we represent the preference relations $\geq_{\chi}$ for individual $\chi$ among the set of street arcs using additive value functions. Let $v_{\chi}$ denotes the value function of individual $\chi$. We define $\geq_{\chi}$ from $v_{\chi}$ as follows:

$$
x_{l m} \geq_{\chi} x_{n t} \text { iff } v_{\chi}\left(x_{l m}\right) \geq v_{\chi}\left(x_{n t}\right)
$$

Where $x_{l m}$ and $x_{n t}$ represent two street arcs and $v_{\chi}$ represents the utility of a street arc for the individual $\chi$. We assume that the utility $u$ of the individual $\chi$ can be represented as a weighted sum of marginal value functions (for a given street edge $x_{i j}$ ):

$$
u_{\chi}\left(x_{i j}\right)=\sum_{k \in A} w_{\chi}^{k} v_{\chi}^{k}\left(x_{i j}\right)
$$

where $w_{\chi}^{k} \in[0,1]$ represents the trade-off of the attribute $k$ (among attributes within the set $A$ that describe the street) for the individual $\chi$. Moreover, given a street attribute $k \in$ $A$, we define a marginal value function $v^{k}: R^{+} \rightarrow[0,1]$.

We assumed for now that such marginal value functions $v_{k}$ and the trade-offs may depend on citizens' preferences and are different for each individual $\chi$, such that the 
function $v_{\chi}^{k}\left(x_{i j}\right)$ represents the utility we assumed the individual $\chi$ give to walk in a street $x_{i j}$ with an attribute $k$ having a specific feature (for example: to walk in a street with a large sidewalk). We defined each partial value function $v$ as a two linear piecewise increasing function representing the importance that each citizen gives to the different attributes of the street with reference to the benefit to traverse that street.

This phase consents to estimate the value functions with reference to the attributes of the street network and to define the trade-offs among the features that describes the walkability of the street network. For example, Figure 5 represents the partial value functions of a hypothetical individual. We can see that the attributes "lighting" and "environmental interest" are the most important in a street with a high walkability benefit (utility).

Considering this utility, we can calculate the cost (see section 5), in terms of effort that a specific individual $\chi$ has to bear in order to walk such street with the equation (8) that we modify as follows.

$$
c_{(y z)}=\sum_{x_{i j} \in p_{y z}} l\left(x_{i j}\right)\left[1-\left(\sum_{k=1}^{m} w_{\chi}^{k}\left(v_{\chi}^{k}\left(x_{i j}\right)\right)^{\rho}\right)^{\frac{1}{\rho}}\right]+c_{0}
$$

Our objective is thus to obtain the cost, i.e. effort to walk in a street network with respect to the utility that a citizen can benefit considering his preferences.

The value function $v$ of the individual $\chi$ becomes:

$$
v_{\chi}\left(x_{i j}\right)=\sum_{k=1}^{m} w_{\chi}^{k}\left(v_{\chi}^{k}\left(x_{i j}\right)\right)
$$

Where $w_{\chi}^{k}$ is the trade-off of the $k$ attribute for the individual $\chi, v_{\chi}^{k}$ is the marginal value of the attribute $k$ for the arc $x_{i j}$.

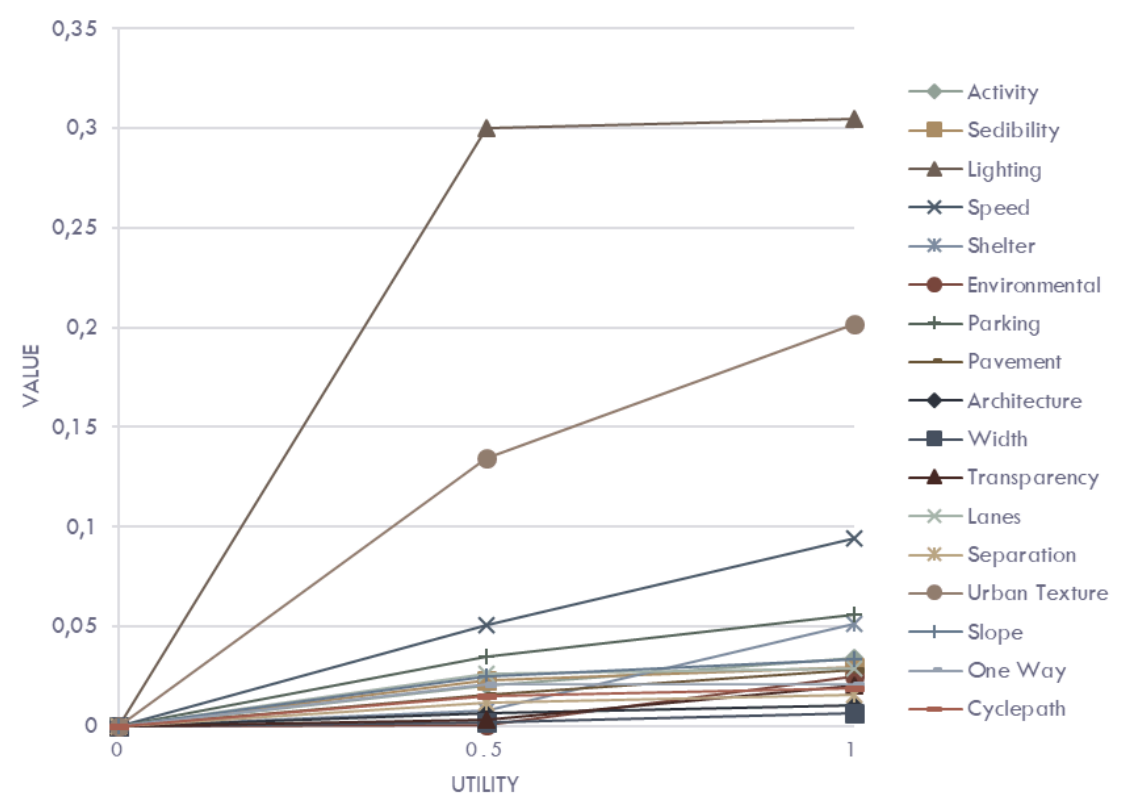

Figure 5: Example of a set of value functions for the different street attributes for a given individual. 


\subsection{Classification of citizens' preferences.}

This phase is aimed to group individuals by considering both their socioeconomic factors and their value function attributes. For this purpose, we need to select the socioeconomic factors (gender, age, profession, health status...) that influence the evaluation of the street network by the individuals. The objective is to establish the minimal set of socioeconomic and behavioural features useful in order to group citizens in clusters (Qamar \& Keane, 2012). To achieve this, we made a rough set feature selection analysis (Jensen \& Shen, 2007; Pawlak, 1982) that simplify the original set of socioeconomic and behavioural features that affect the choice to walk by reducing the number of unnecessary features albeit retaining accuracy. The original set of features was composed by socioeconomic (age, sex, job,...) and behavioural factors (sport and leisure behaviours and activity-based behaviours) collected through the questionnaire. The rough set analysis feature selection suggested a feature subset composed of 9 socioeconomic and behavioural attributes (instead of 14) that have to be considered for the cluster analysis: (1) sport routine, (2) work/study routine of walking, (3) free time routine of walking, (4) errands routine, (5) health status, (6) sex, (7) age, (8) job, (9) neighbourhood of residence. Then, we performed a cluster analysis of the values of value functions together with these 9 factors. Cluster analysis consents us to identify groups of citizens which give the same importance to the streets' attributes and have similar socioeconomic and behavioural profile.

We chose to calculate clusters with the Hierarchical Cluster (HC) method (by using the R software) which consents to calculate clusters without knowing a-priori the number of groups. Having to deal with numerical (value functions) and categorical data (socioeconomic and behavioural information), we used the Gower dissimilarity index (Gower, 1971), suggested in such cases in order to define distances and centroids. The Gower index calculates for each variable a distance metric fitting that type of variable, then the distance is scaled between 0 and 1 (normalised scale with quantitative data and dummy variables for nominal data). The distance matrix is calculated using a linear combination with user-specified weights (an average).

Finally, in order to generate groups, we chose the Ward (1963) classification method that minimizes the total within-cluster variance. Among the cluster agglomeration methods Ward is considered one of the more appropriate for the unsupervised classification as it merges at each step the pair of clusters with minimum between-cluster distance.

Cluster analysis silhouette index suggested us to classify the population into 11 clusters, represented in Errore. L'origine riferimento non è stata trovata. with different colours. Cluster dendrogram (Figure 5) shows the order in which clusters are joined: the $\mathrm{x}$ axis represented the closeness of individuals in the same cluster, while the height of the dendrogram indicates the dissimilarity between clusters.

The citizens composing these 11 clusters vary and differ from the traditional statistical classifications of people by age and gender. In brief, the cluster analysis consents to group different categories of people considering both their preferences and needs; needs are represented by socioeconomic factors while preferences are learnt by value functions. In order to discuss the results with a hypothetical decision maker, we proposed to synthesise the value functions of the single 17 attributes (Table 1) into three criteria (safety, comfort, pleasantness) defined according to the walkability literature (Blečić, Congiu, et al., 2020) and considering the specificity of our case study. The hypothesis here is that a potential client of such a study should be able to see each cluster 
characterized by these three criteria (which are easily perceived). This synthesis is visible in Table 4 and is done aggregating linearly the values. This is possible because of the separability and independence of the 17 basic attributes. $\alpha_{j} \in A$.

We use an example with two attributes of the street for demonstrating that these two conditions (separability and independence) are satisfied: one coming from our model and another external and not included in our model. The "width of the sidewalk" is a separable attribute because if we consider two street edges, $K$ and $H$, having identical variables with respect to the walkability attributes $\alpha_{j} \in A$ except sidewalk width, we can assert that $K$ is preferred to $H$ only because the sidewalk of the street $K$ is larger than the sidewalk of the street $H$.

On the contrary, if we consider the attribute "number of vehicle entrance" (not included in our model) we can show that such attribute is not separable. For example, two street edges $K$ and $H$ having identical variables with respect to the walkability attributes $\alpha_{i, \ldots, j} \in A$ except $n$.Vehicle entrance $\notin A$, we can assert that $K$ is indifferent to $H$ even if the number of vehicle entrance of the street $K$ is different from the number of vehicle entrance of the street $H$.

The synthesis of attributes into criteria (such as those used in this paper: safety, comfort and pleasantness in Errore. L'origine riferimento non è stata trovata.), serves the purpose of giving priorities to certain goals revealed during the discussion with the decision makers and aims to prioritize the improvement of specific features $(i . e$. the attributes: width of the sidewalk, paving, ...) in the design of a public policy. This methodological choice corresponds to a degree of freedom between the analyst and the decision maker giving more legitimation to the decision process.

Table 3: Criteria of walkability and related combining attributes.

\begin{tabular}{|l|c|c|c|}
\hline Attribute & \multicolumn{3}{|c|}{ CRITERIA } \\
\hline Width of sidewalk (accessible) & safety & pleasantness & comfort \\
\hline Cyclability & & & $\bullet$ \\
\hline Car speed limit & $\bullet$ & & \\
\hline Width of the roadway & $\bullet$ & & \\
\hline One way street & $\bullet$ & & \\
\hline On-street parking & $\bullet$ & & \\
\hline $\begin{array}{l}\text { Paving (quality and degree of } \\
\text { maintenance) }\end{array}$ & & & $\bullet$ \\
\hline Path slope & & & $\bullet$ \\
\hline Lighting & $\bullet$ & & \\
\hline Shelter and shade & & & \\
\hline $\begin{array}{l}\text { Separation of pedestrian route from } \\
\text { car roadway }\end{array}$ & $\bullet$ & & \\
\hline Opportunity to sit & & & \\
\hline Urban texture & & & \\
\hline Frequency of services and activities & $\bullet$ & & \\
\hline $\begin{array}{l}\text { Transparency and permeability of } \\
\text { the public-private space }\end{array}$ & $\bullet$ & & \\
\hline $\begin{array}{l}\text { Interest from an environmental } \\
\text { point of view }\end{array}$ & & & \\
\hline $\begin{array}{l}\text { Interest from an architectural and } \\
\text { urban viewpoint }\end{array}$ & & & \\
\hline
\end{tabular}




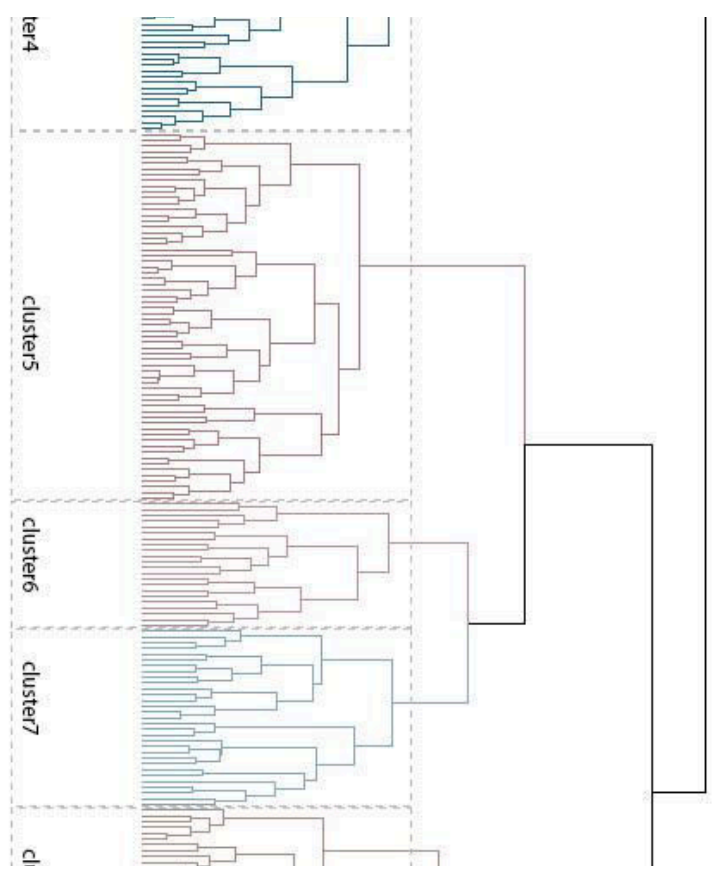

Figure 6:Cluster dendrogram with the subdivision in 11 groups of citizens. 
Table 4: Synthesis of the values (medium and maximum) of the criteria for the clusters of citizens, as synthesized in value functions in Figure 8.

\begin{tabular}{lllllll}
\hline Clusters & \multicolumn{2}{c}{ Safety } & \multicolumn{2}{c}{ Comfort } & \multicolumn{2}{c}{ Pleasantness } \\
& Medium & Max & Medium & Max & Medium & max \\
\hline $\mathbf{1}$ & 0,449 & 0,434 & 0,366 & 0,340 & 0,186 & 0,226 \\
\hline $\mathbf{2}$ & 0,050 & $\mathbf{0 , 0 7 0}$ & 0,050 & $\mathbf{0 , 2 0 6}$ & 0,900 & $\mathbf{0 , 7 2 4}$ \\
\hline $\mathbf{3}$ & 0,502 & 0,505 & 0,428 & $\mathbf{0 , 4 0 1}$ & 0,069 & $\mathbf{0 , 0 9 4}$ \\
\hline $\mathbf{4}$ & 0,411 & 0,378 & 0,357 & 0,317 & 0,232 & 0,305 \\
\hline $\mathbf{5}$ & 0,204 & 0,236 & 0,102 & 0,241 & 0,694 & 0,523 \\
\hline $\mathbf{6}$ & 0,433 & 0,367 & 0,383 & 0,360 & 0,183 & 0,272 \\
\hline $\mathbf{7}$ & 0,488 & $\mathbf{0 , 5 1 5}$ & 0,270 & 0,264 & 0,242 & 0,220 \\
\hline $\mathbf{9}$ & 0,353 & 0,370 & 0,367 & 0,354 & 0,280 & 0,276 \\
\hline $\mathbf{1 0}$ & 0,464 & 0,456 & 0,426 & 0,384 & 0,110 & 0,160 \\
\hline $\mathbf{1 1}$ & 0,359 & 0,375 & 0,329 & 0,308 & 0,312 & 0,317 \\
\hline & 0,470 & 0,466 & 0,419 & 0,389 & 0,110 & 0,144 \\
\hline
\end{tabular}

According to these assumptions in Figure 7 we synthesized some of the socioeconomic factors that describe the 11 clusters (in which the peaks represent the quantity of each component), while in Figure 8 and in Table 4 we illustrated the value functions of the 3 walkability criteria for each cluster of citizens.

By combining these two figures (Figure 7 and 8) together with Table 4 we can draw important suggestions for the policy making process. For example, cluster 2 and 3 are prevalently composed by women $(80 \%)$ that give an inverse importance to the pleasantness of the street (respectively 0,7 and 0,09 ). Cluster 2 is composed prevalently of young ( $<40$ years old) unemployed women $(60 \%)$ living in the city centre $(80 \%)$ that play sports 2-3 times in a week (60\%) for whom the pleasantness of the street assumes a fundamental role in the choice to walk (value 0,7 ). While the cluster 3 , consisting of working women $(80 \%)$ with some health problems $(60 \%)$ that rarely play sports $(80 \%)$, gives a very low importance to the pleasantness of the street $(0,09)$ and considers more important the safety $(0,5)$ and comfort $(0,4)$ criteria.

Furthermore, there is a significant difference between the walkability values given by men and women that usually plays sports and have not serious health problems (represented by cluster 4 and cluster 7). Cluster 4 gives same importance to the walkability criteria safety, comfort and pleasantness; it is composed by men (100\%) workers $(55 \%)$ and unoccupied students $(45 \%)$ without serious health problems $(60 \%$ none and $40 \%$ not many problems) that usually play sports 2-3 times a week (75\%). Differently, citizens in cluster 7 (healthy working women (65\%) and students (35\%)) give high importance to the safety criteria $(0,5)$ and lower importance to comfort and pleasantness $(0,25)$.

Moreover, cluster 10 is prevalently composed by retired (35\%) citizens (55\% men and $45 \%$ women) with health problem (60\% serious handicaps and $15 \%$ not many health problems) that never play sports $(90 \%)$ and give the major value to safety criterion $(0,37)$ and the same value to comfort and pleasantness criteria $(0,3)$.

Considering all the citizens, safety is the higher valued criterion with a mean of 0,38 , compared to comfort (mean of 0,32 ) and pleasantness characterized by the lowest value (mean of 0,30). The criterion comfort is generally considered of medium importance with the maximum importance given by the cluster $3(0,4)$, and the minimum value given by 
the cluster $2(0,2)$. While the importance of criteria pleasantness and safety varies considerably for all the clusters (from 0 to 0,7 ). Pleasantness is considered as fundamental for cluster $2(0,7)$, while cluster 3 gives minimum importance to this criterion $(0,09)$. Finally, safety is the most important criterion for the citizens of cluster 7 : women (students and young employees) living in city centre or in the peri-urban areas of the city, playing sports 3 or more times in a week.

These are only some of the considerations the policy maker can do with these data.
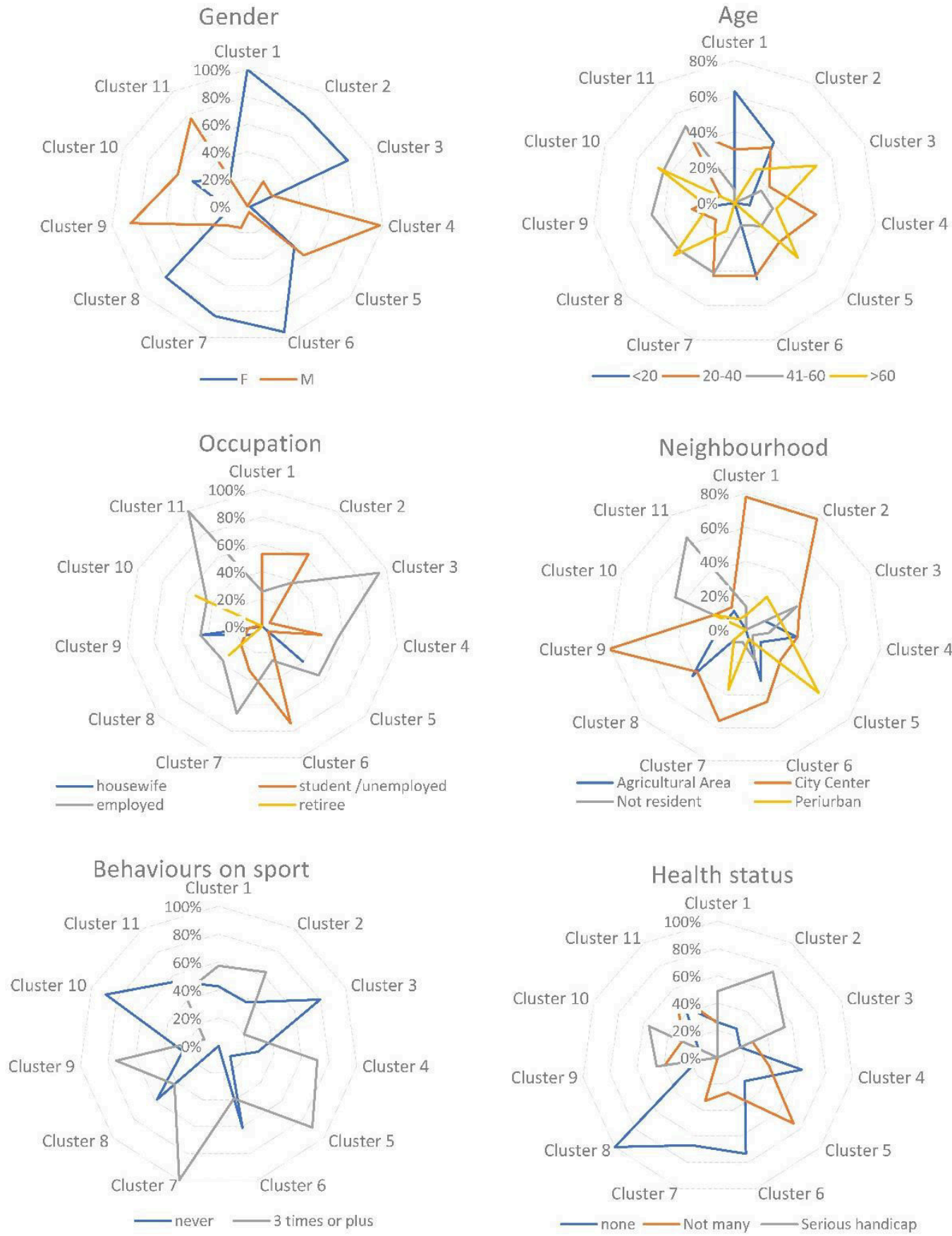

Figure 7: Radar chart of the socioeconomic factors describing clusters. 
CLUSTER 1

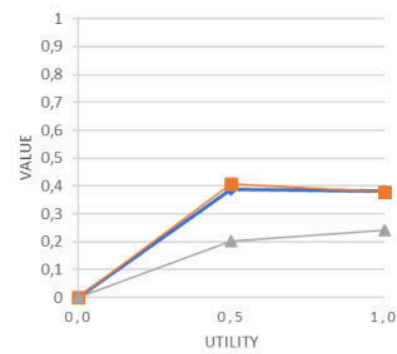

CLUSTER4

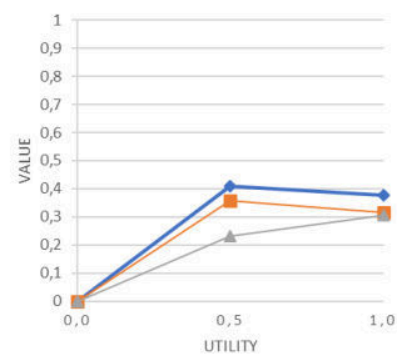

CLUSTER 7

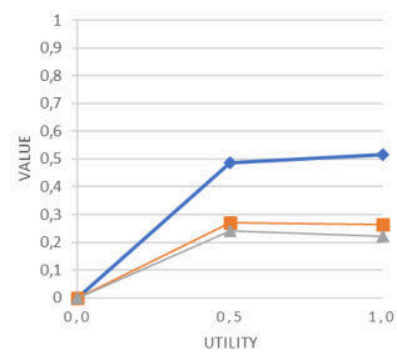

CLUSTER 10

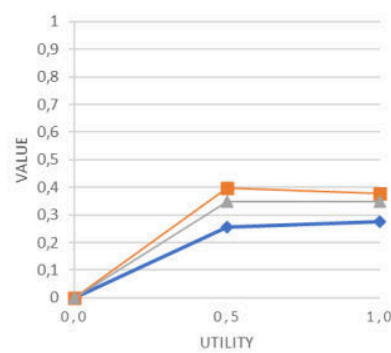

CLUSTER2

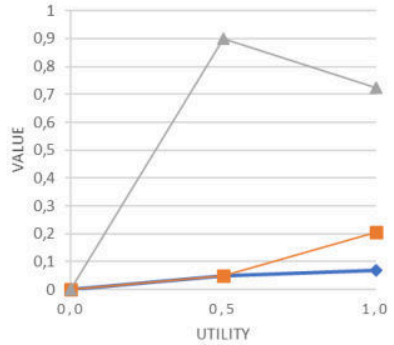

CLUSTER 5

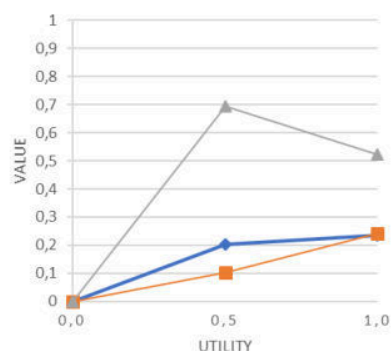

CLUSTER 8

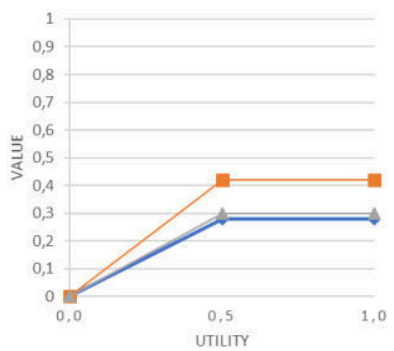

CLUSTER 11

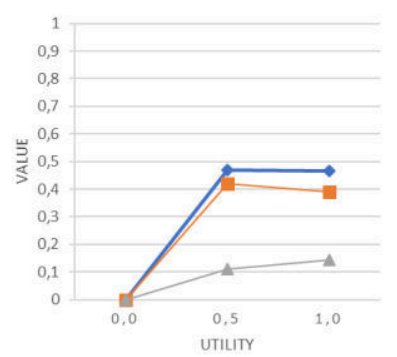

CLUSTER3

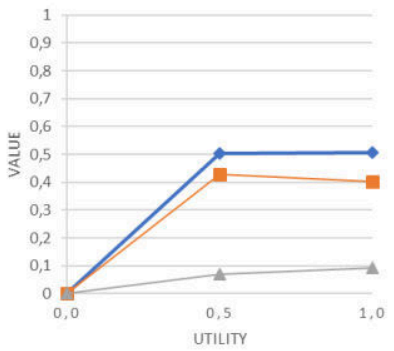

CLUSTER 6

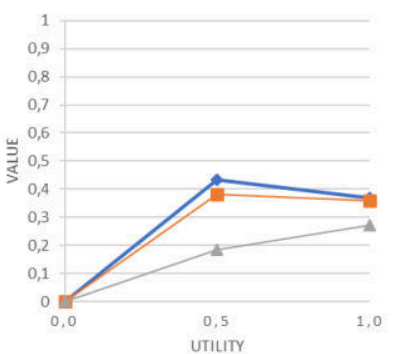

CLUSTER 9

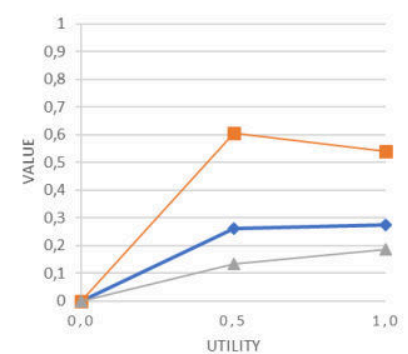

- efficiency and confort

$₫$ pleasantness

Figure 8: Synthesis of value functions of the walkability criteria for the 11 clusters of citizens.

\section{Decision maps}

The design of a decision map implies to consider spatial features in a MCDA model, able to synthesize policy maker preferences in a map.

Here we propose to design decision maps for the design of public policies aimed to improve the capability to walk in the city for different clusters of citizens. It is an experimental phase which aims to synthesize citizens' values in space by combining the CAWS method, the GIS tools and the results of the analysis of citizens' values ( $4^{\text {rd }}$ phase of the method, see Figure 2). 
Our main claim in this paper is the necessity to consider value functions and the differences among individuals in order to analyse citizens' welfare components such as the walkability. Especially, we expressed the individuality of citizens by the values they give to the walkability attributes and their socioeconomic and behavioural characteristics. Both these elements are useful in order to represent citizens' freedom to walk in a street. For this reason, we modified the former normative value function used in CAWS model by considering the values (trade-off) that each cluster of citizens gives to the different 17 street attributes. As a result, we obtain a set of decision maps that highlight the walkability of the 11 clusters of citizens. The reader interested can see all the 11 maps (here), and a .gif. showing the differences between maps at this link. In Figure 9 we made an example of decision maps for the cluster 3 and the cluster 9. For each cluster we built three maps representative of the walkability to reach retail and commerce, services and green and recreational facilities.

Figure 9: Decision maps for cluster 3 and cluster 9 and difference-map among the two clusters (3-9).

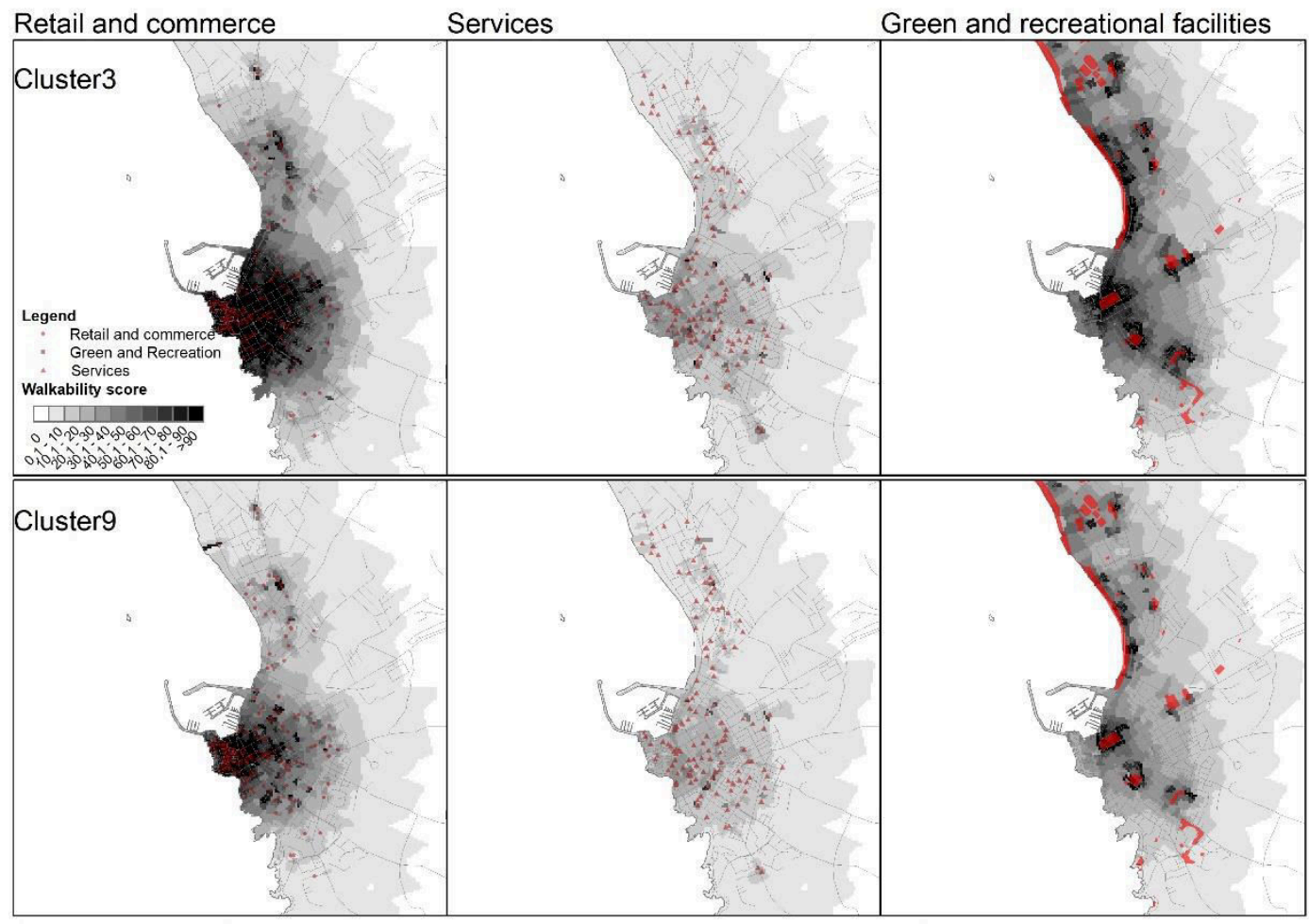

Difference-map between Cluster 3 Walkability score and Cluster 9 Walkability score

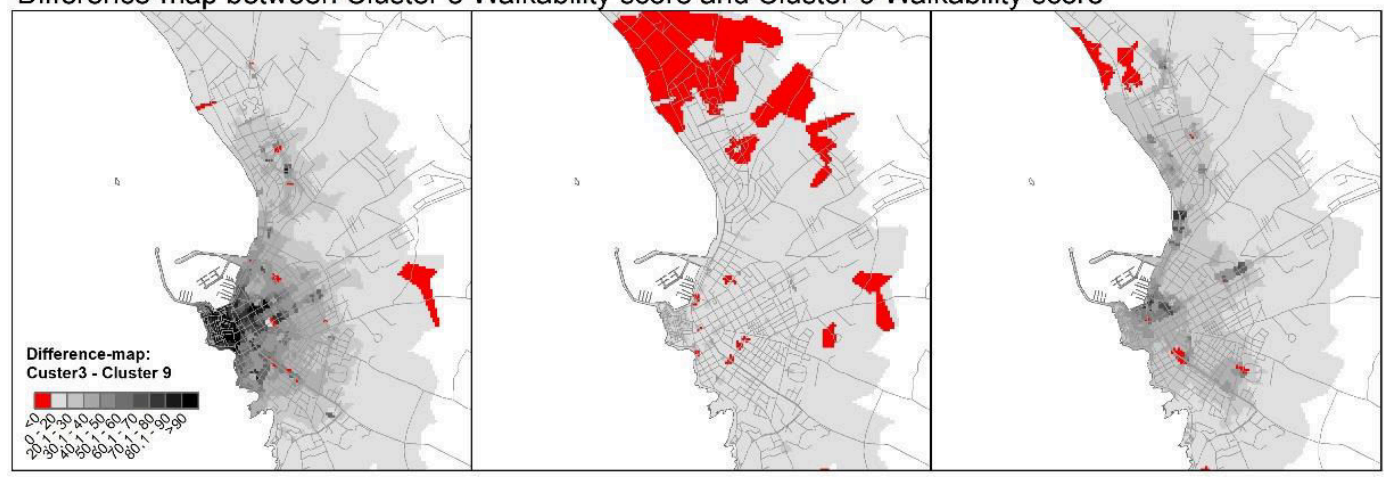


Among the possible comparisons between decision maps, we want to linger on the cluster 9 , composed by sporty men, living in the centre, for whom the comfort attributes are the most important, and cluster 3, composed by women, nonathletic, not resident, with some health problems for whom the pleasantness criteria is not important. The comparison among citizens of cluster 9 and cluster 3 is interesting for the Retail and Commerce map and for the Green and Recreational Facilities map which result visibly different for the distribution of walkability. If the Cluster 3 has a good walkability score in the historic centre and the central area of the city for retail and commerce facilities, Cluster 9's decision map shows important urban limits both in the peri-urban areas and the most central areas. For the citizens in cluster 9, only the historical centre has a good walkability for retail and commerce facilities, while the capability to walk to green and recreational facilities is limited: as shown in the decision map only the streets close to the parks and the waterfront offer (to this group of citizens) an easy and safe way to reach such facilities. The service decision map reveals important limits for both cluster 9 and cluster 3 , but the cluster 9 is the most affected by the urban limits to walk for reach services, especially in the peri-urban areas.

In order to better highlight the different distribution of walkability among two decision maps, we elaborate a difference-map (Figure 9) representing the mathematical difference of walkability score for the two clusters. The difference map highlights the gain (in grey scale) or the loss (in red) of walkability score for two groups of citizens. This map represents how a policy that chooses to meet the preferences and needs of a group of citizens in all the city, causes the loss of pedestrian accessibility for others. For example, by observing the difference-map in Figure 9, if a policy maker decides to follow the preferences of cluster 9 , then the cluster 3 group will lose completely his ability to walk in the red areas of the map. Such areas of the city can be then considered as disadvantaged areas for this group of citizens.

The decision maps reported in the paper represent the current situation of the city of Alghero and highlighted how different citizens have different freedoms to act (i.e. different urban capabilities) in the city, while citizens in the same cluster experience the city in the same way. However, decision maps can be elaborated considering the introduction of a future policy. In such a way decision maps act as a decision-making supporting tool as they will consent to discuss with a policy maker about the difference that a public policy will entail on well-being for the different groups of citizens. Indeed, the same set of actions will condition differently the development of well-being of different groups of citizens.

Starting from these assumption, the design of a public policy can be implemented in two ways: 1) considering the values of one cluster of citizen in city planning; 2 ) considering a specific area of the city (for example the historical centre) and the preferences of a particular group of citizens. The methodological framework proposed in this paper can then be used by the policy makers in order to analyse the future effects of a public policy, then to plan public policies aimed to meet the preference of specific groups of citizens by considering the limiting effects on well-being for other groups.

\section{Conclusions.}

In this paper we introduced some advancements in the methodological background of walkability assessment tools and their use for policy design. In this regard, we proposed a 
decision-aiding method aimed to evaluate the capability to walk of citizens by considering both contextual features and subjective elements. According to the Capability Approach, we claim that welfare components (as the walkability) must be analysed by a multidimensional and subjective approach, attentive to individual diversity. We resorted to MAVT, that is a family of multi-criteria decision analysis methods aimed to evaluate alternatives and to measure differences of preferences. Further on we used a preference disaggregation method in order to learn the citizens' value functions using examples of real behaviour and stated preferences.

For urban planners and designers involved in the formulation of public policies, as well as for decision makers, it becomes fundamental to be aware of preferences and values in order to achieve spatial and social justice in the access to urban opportunities. Moreover, understanding how space and the environment influence citizens' preferences and values is a fundamental step for designing legitimated public policies. Values derived from individual preferences, consent to assess the desirability of any possible alternative and define what decision makers care about in a specific decision situation.

Hence, in order to demonstrate our initial assumption that welfare needs to be analysed from a multidimensional and subjective point of view, we elaborate value functions and decision maps representative of the preferences to walk in the city of different groups of citizens. Such synthesis of data consents to compare preferences among groups and to have useful and legitimated information for the policy design. Clustering groups of citizens along their subjective preferences, allows a policy maker to better choose among alternative policies and/or to build a set of actions tailor-made for a specific context. In fact, it is not sufficient to know that a walkable environment is a good place, we need to know which are the individuals that will use such space in order to address its design and we need to know their preferences in order to legitimate the public policy.

The reader should note that the results for our experimental validation case study (the Alghero city) hold for this specific case. A different context and other citizens observed will yield different results. The walkability findings about Alghero are not replicable elsewhere. What can be replicated is the proposed methodology in order to highlight the diversity among individuals and how such diversities influence the relation among citizens and the city.

For this reason, besides a decision analysis model, the method proposed in this paper can result useful in order to build spatial policies legitimated by citizens. It supports policy makers in the definition of policies addressed to citizens' needs (their socio-economic characteristics and behaviours) and preferences (their values). In order to reach this goal, we adopted and suggest three main methodological strategies.

First, we recommend to synthesize the urban attributes into criteria (such as those used in this paper: safety, comfort and pleasantness) that help decision makers to deal with the specific problem. This serves the purpose of giving priorities to certain goals revealed during the discussion with the decision maker and consequently to prioritize the improvement of specific features in the design of a public policy. This methodological choice corresponds to a degree of freedom between the analyst and the decision maker giving more legitimation to the decision process.

Second, we recommend the elaboration of decision maps representative of the spatial multiple criteria analysis of urban walkability for different groups of citizens. Decision maps, besides offering an analytical tool, can be useful for participative processes with citizens. In fact, the cartographic representation of the citizens' values help policy makers and citizens to visualize and better understand how spatial inequalities are distributed in 
the city. Value functions and Decision maps should be validated with a focus group of citizens and compared with the preferences of city governors and of policy designers. Furthermore, we suggest to involve mobility experts, urban planners and designers in the process of innovative design and selection of alternative policies in order to better define the determinants of the marginal cost over alternatives and the feasibility of policy actions.

Third, we recommend different analysis methods (value functions, radar charts and decision maps) in order to compare groups of citizens' preferences. Such methods highlight useful information for decision making. Especially, a policy maker can benefit from this decision analysis because: 1) he/she can depict the areas of the city that need new public policies for a specific group of citizen; 2) he/she can know how much will be the benefit or the limit of every single group of citizen for the development of a specific public policy; 3 ) he/she can know, before implementing a policy, the effective groups of people that will agree on a policy and legitimate a public spending.

The authors acknowledge the need to develop the proposed methodology in several directions. First, we need to test our method in different contexts in order to build a protocol useful for the analysis of different case studies. The scalability of the proposed method in other cities should take into account both the specificity of the context and the different composition of citizens. For this reason, the model should be associated to context-embedded specific criteria and attributes characterising walkability and it should consider the composition of the citizens for the data collection. Especially, we suggest to collect data considering a sample statistically significant with reference to the policy design problem.

Moreover, different urban and environmental public policy decision problems can benefit from the application of the proposed method. By substituting the walkability analysis with a specific decision analysis model, and then following the subsequent steps of the method (Figure 2: perform the analysis of citizens' values, the design of decision maps and provide recommendation for the policy design) policy makers could implement this method to deal with other policy design problems. For example, we test this method with the purpose to analyse the preferences of the tourists regarding the quality of the urban and environmental assets in order to build innovative non-seasonal tourist policies.

Another future work will be to focus upon the spatial correlation among groups of citizens with the same preferences and needs. The research question will be: do urban features influence the confluence in the same urban area of groups of citizens with the same needs and preferences?

Moreover, further work will analyse the spatial dependence of value functions. Even if the method proposed in this paper is spatially dependent, we are conscious that the use of a single value function for the study area ignores the possibility that the form of the function may depend on the local context (i.e. location of the alternatives). In other words, the question we are interest to answer is: if the same citizen is asked to evaluate the same alternative (in our case, the walkability of a street) in two different areas of a city, will he/she have different preferences (that is, different value functions) and therefore give different priorities for the fulfilment of his well-being? We claim it is the case, but the analysis of such hypothesis will be the subject of further research. 


\section{Bibliography}

Adlakha, D. (2017). Quantifying the Modern City: Emerging Technologies and Big Data for Active Living Research. Frontiers in Public Health, 5(May), 105. https://doi.org/10.3389/fpubh.2017.00105

Alfonzo, M. A. (2005). To walk or not to walk? The hierarchy of walking needs. Environment and Behavior. https://doi.org/10.1177/0013916504274016

Ananda, J., \& Herath, G. (2003). Incorporating stakeholder values into regional forest planning: A value function approach. Ecological Economics, 45(1), 75-90.

Arnberger, A., \& Eder, R. (2011). The influence of age on recreational trail preferences of urban green-space visitors: a discrete choice experiment with digitally calibrated images. Journal of Environmental Planning and Management. https://doi.org/10.1080/09640568.2010.539875

Bader, M. D. M., Mooney, S. J., Lee, Y. J., Sheehan, D., Neckerman, K. M., Rundle, A. G., \& Teitler, J. O. (2015). Development and deployment of the Computer Assisted Neighborhood Visual Assessment System (CANVAS) to measure health-related neighborhood conditions. Health and Place, 31, 163-172. https://doi.org/10.1016/j.healthplace.2014.10.012

Badland, H., White, M., MacAulay, G., Eagleson, S., Mavoa, S., Pettit, C. J., \& GilesCorti, B. (2013). Using simple agent-based modeling to inform and enhance neighborhood walkability. International Journal of Health Geographics, 12(58), 110. https://doi.org/10.1186/1476-072X-12-58

Barton, H., Thompson, S., Burgess, S., \& Grant, M. (2015). The Routledge Handbook of Planning for Health and Well-Bein. Shaping a sustainable and healthy future Edited (H. Barton, S. Thompson, S. Burgess, \& M. Grant, Eds.). Taylor \& Francis.

Beinat, E. (1997). Value Functions for Environmental Management. Dordrecht: Springer.

Bejleri, I., Steiner, R. L., Fischman, A., \& Schmucker, J. M. (2011). Using GIS to analyze the role of barriers and facilitators to walking in children's travel to school. URBAN DESIGN International, 16(1), 51-62. https://doi.org/10.1057/udi.2010.18

Belton, V., \& Stewart, T. J. (2002). Multiple criteria decision analysis: an integrated approach. Springer-science+business Media.

Blečić, I., Cecchini, A., Congiu, T., Fancello, G., Talu, V., \& Trunfio, G. A. (2015). Operationalising urban capabilities: the case of walkability. Proceedings of the 2015 HDCA Conference - Capabilities on the Move: Mobility and Aspirations, Washington, September 10-13, 2015.

Blečić, I., Cecchini, A., Congiu, T., Fancello, G., Talu, V., \& Trunfio, G. A. (2020). Capability-wise walkability evaluation as an indicator of urban peripherality. Environment and Planning B: Urban Analytics and City Science. https://doi.org/10.1177/2399808320908294

Blečić, I., Cecchini, A., Congiu, T., Fancello, G., \& Trunfio, G. A. (2015). Evaluating walkability: a capability-wise planning and design support system. International Journal of Geographical Information Science, 29(8), 1350-1374. https://doi.org/10.1080/13658816.2015.1026824

Blečić, I., Cecchini, A., Fancello, F., \& Fancello, G. (2015). An Evaluation and Design Support System for Urban Walkability. In R. Ferreira, J. and Goodspeed (Ed.), Planning Support Systems and Smart Cities - CUPUM 2015: The 14th International Conference on Computers in Urban Planning and Urban Management, Cambridge, MA USA July 7-10, 2015 (pp. 51-66). Retrieved from 
https://pdfs.semanticscholar.org/00c4/970c00aa2c45bbe265c2abab2bbb7bfb4173.p df

Blečić, I., Cecchini, A., \& Talu, V. (2013). The Capability Approach in Urban Quality of Life and Urban Policies: Towards a Conceptual Framework. In S. Serreli (Ed.), City Project and Public Space (pp. 269-288). https://doi.org/10.1007/978-94-007-60370_17

Blečić, I., Cecchini, A., \& Trunfio, G. A. (2015). Towards a design support system for urban walkability. Procedia Computer Science, 51(1), 2157-2167. https://doi.org/10.1016/j.procs.2015.05.489

Blečić, I., Congiu, T., Fancello, G., \& Trunfio, G. A. (2020). Planning and Design Support Tools for Walkability: A Guide for Urban Analysts. Sustainability, 12(11), 4405. https://doi.org/10.3390/su12114405

Bouyssou, D., Marchant, T., Pirlot, M., Perny, P., Tsoukiàs, A., \& Vincke, P. (2000). Evaluation and decision models: a critical perspective. Kluwer Academy Publishers.

Buck, C., Pohlabeln, H., Huybrechts, I., De Bourdeaudhuij, I., Pitsiladis, Y., Reisch, L., \& Pigeot, I. (2011). Development and application of a moveability index to quantify possibilities for physical activity in the built environment of children. Health and Place, 17(6), 1191-1201. https://doi.org/10.1016/j.healthplace.2011.08.011

Carlson, J. A., Sallis, J. F., Conway, T. L., Saelens, B. E., Frank, L. D., Kerr, J., ... King, A. C. (2012). Interactions between psychosocial and built environment factors in explaining older adults' physical activity. Preventive Medicine. https://doi.org/10.1016/j.ypmed.2011.10.004

Carr, L. J., Dunsiger, S. I., \& Marcus, B. H. (2010). Walk score ${ }^{\mathrm{TM}}$ as a global estimate of neighborhood walkability. American Journal of Preventive Medicine, 39(5), 460463.

Carr, L. J., Dunsiger, S. I., \& Marcus, B. H. (2011). Validation of Walk Score for estimating access to walkable amenities. British Journal of Sports Medicine. https://doi.org/10.1136/bjsm.2009.069609

Cervero, R., \& Duncan, M. (2003). Walking, Bicycling, and Urban Landscapes: Evidence from the San Francisco Bay Area. American Journal of Public Health, 93(9), 1478 1483. https://doi.org/10.2105/AJPH.93.9.1478

Chakhar, S., \& Martel, J. M. (2003). Enhancing Geographical Information Systems Capabilities with Multi-Criteria Evaluation Functions. Journal of Geographic Information and Decision Analysis, 7(2), 47-71. https://doi.org/10.1016/j.chb.2011.11.013

Chan, E. T. H., Schwanen, T., \& Banister, D. (2019). The role of perceived environment, neighbourhood characteristics, and attitudes in walking behaviour: evidence from a rapidly developing city in China. Transportation, (0123456789). https://doi.org/10.1007/s11116-019-10062-2

Clifton, K. J., Livi Smith, A. D., \& Rodriguez, D. (2007). The development and testing of an audit for the pedestrian environment. Landscape and Urban Planning, 80(1-2), 95-110. https://doi.org/10.1016/j.landurbplan.2006.06.008

Dasgupta, P. (2001). Human Well-Being and the Natural Environment. New York: Oxford Paperbacks.

Ewing, R., \& Handy, S. L. (2009). Measuring the Unmeasurable: Urban Design Qualities Related to Walkability. Journal of Urban Design, 14(1), 65-84. https://doi.org/10.1080/13574800802451155 
Ferretti, V. (2016). From stakeholders analysis to cognitive mapping and Multi-Attribute Value Theory: An integrated approach for policy support. European Journal of Operational Research. https://doi.org/10.1016/j.ejor.2016.02.054

Ferretti, V., Bottero, M., \& Mondini, G. (2014). Decision making and cultural heritage: An application of the Multi-Attribute Value Theory for the reuse of historical buildings. Journal of Cultural Heritage, 15(6), 644-655.

Ferretti, V., Pluchinotta, I., \& Tsoukiàs, A. (2019). Studying the generation of alternatives in public policy making processes. European Journal of Operational Research. https://doi.org/10.1016/j.ejor.2018.07.054

Forsyth, A. (2015). What is a walkable place? The walkability debate in urban design. Urban Design International, 20(4), 274-292. https://doi.org/10.1057/udi.2015.22

Forsyth, A., \& Krizek, K. J. (2010). Promoting walking and bicycling: Assessing the evidence to assist planners. Built Environment. https://doi.org/10.2148/benv.36.4.429

Forsyth, A., Michael Oakes, J., Lee, B., \& Schmitz, K. H. (2009). The built environment, walking, and physical activity: Is the environment more important to some people than others? Transportation Research Part D: Transport and Environment. https://doi.org/10.1016/j.trd.2008.10.003

Frank, L. D., Sallis, J. F., Conway, T. L., Chapman, J. E., Saelens, B. E., \& Bachman, W. (2006). Many pathways from land use to health. Journal of the American Planning Association, 72(1), 75-87. https://doi.org/10.1080/01944360608976725

Frank, L. D., Sallis, J. F., Saelens, B. E., Leary, L., Cain, K., Conway, T. L., \& Hess, P. M. (2010). The development of a walkability index: application to the Neighborhood Quality of Life Study. British Journal of Sports Medicine, 44(13), 924-933. https://doi.org/10.1136/bjsm.2009.058701

Fürnkranz, J., \& Hüllermeier, E. (2010). Preference Learning: an introduction. Springer Berlin.

Gardner, K., Johnson, T., Buchan, K., \& Pharoah, T. (1996). Developing a pedestrian strategy for London. Transport Policy and Its Implementation: Proceedings of Seminar B Held at the PTRC European Transport Forum, Brunel University, England, 2-6 September 1996., 400. Retrieved from http://www.worldcat.org/title/transport-policy-and-its-implementation-proceedingsof-seminar-b-held-at-the-ptrc-european-transport-forum-brunel-university-uxbridgeengland-2-6-september-1996/oclc/924703888\#.WcEW18PVn00.mendeley

Garin, N., Olaya, B., Miret, M., Ayuso-Mateos, J. L., Power, M., Bucciarelli, P., \& Haro, J. M. (2014). Built environment and elderly population health: a comprehensive literature review. Clinical Practice and Epidemiology in Mental Health : CP \& EMH, 10, 103-115. https://doi.org/10.2174/1745017901410010103

Gebel, K., Bauman, A. E., Sugiyama, T., \& Owen, N. (2011). Mismatch between perceived and objectively assessed neighborhood walkability attributes: Prospective relationships with walking and weight gain. Health and Place. https://doi.org/10.1016/j.healthplace.2010.12.008

Gehl, J. (2010). Cities for People. Washington, DC: Island Press.

Goodin, R. E., Moran, M., \& Rein, M. (2008). The Oxford Handbook of Public Policy. In R. E. Goodin, M. Moran, \& M. Rein (Eds.), The Oxford Handbook of Public Policy. https://doi.org/10.1093/oxfordhb/9780199548453.001.0001

Gower, J. C. (1971). A General Coefficient of Similarity and Some of Its Properties. Biometrics, 27(4), 857-871. 
Greco, S., Kadziński, M., Mousseau, V., \& Słowiński, R. (2012). Robust ordinal regression for multiple criteria group decision: UTA GMS-GROUP and UTADIS GMS-GROUP. Decision Support Systems, 52(3), 549-561. https://doi.org/10.1016/j.dss.2011.10.005

Guo, Z., \& Loo, B. P. Y. (2013). Pedestrian environment and route choice: evidence from New York City and Hong Kong. Journal of Transport Geography, 28, 124-136. https://doi.org/10.1016/j.jtrangeo.2012.11.013

Haab, T. C. ., McConnell, K. E. ., \& Bishop, R. C. (2002). Valuing Environmental and Natural Resources. In Measurement. Northampton: Edward Elgar Publishing Limited.

Handy, S. L. (1997). Urban form and pedestrian choices: Study of Austin neighborhoods. Transportation Research Record. https://doi.org/10.1177/0361198196155200119

Hanley, N., Mourato, S., \& Wright, R. E. (2002). Choice Modelling Approaches: A Superior Alternative for Environmental Valuatioin? Journal of Economic Surveys, 15(3), 435-462. https://doi.org/10.1111/1467-6419.00145

Iacono, M., Krizek, K. J., \& El-Geneidy, A. (2010). Measuring non-motorized accessibility: issues, alternatives, and execution. Journal of Transport Geography, 18(1), 133-140. https://doi.org/10.1016/j.jtrangeo.2009.02.002

Jacquet-Lagreze, E., \& Siskos, J. (1982). Assessing a set of additive utility functions for multicriteria decision-making, the UTA method. European Journal of Operational Research, 10(2), 151-164. https://doi.org/10.1016/0377-2217(82)90155-2

Jensen, R., \& Shen, Q. (2007). Rough set-based feature selection: A review. In Rough Computing: Theories, Technologies and Applications. https://doi.org/10.4018/9781-59904-552-8.ch003

Kadziński, M., Greco, S., \& Słowiński, R. (2012). Selection of a representative value function in robust multiple criteria ranking and choice. European Journal of Operational Research, 217(3), 541-553. https://doi.org/10.1016/j.ejor.2011.09.032

Kaufman, L., \& Rousseeuw, P. J. (2005). Finding Groups in Data: An Introduction to Cluster Analysis (Wiley Series in Probability and Statistics). In Finding Groups in Data. https://doi.org/10.1007/s13398-014-0173-7.2

Keeney, R. L., \& Raiffa, H. (1976). Decisions with multiple objectives. Preference and Value Tradeoffs (1993rd ed.). Cambridge University Press.

Krizek, K. J. (2003). Operationalizing Neighborhood Accessibility for Land Use-Travel Behavior Research and Regional Modeling. Journal of Planning Education and Research, 22(3), 270-287. https://doi.org/10.1177/0739456X02250315

Lee, C., \& Moudon, A. V. (2006). The 3Ds + R: Quantifying land use and urban form correlates of walking. Transportation Research Part D: Transport and Environment, 11(3), 204-215. https://doi.org/10.1016/j.trd.2006.02.003

Lidouh, K. (2013). On the motivation behind MCDA and GIS integration. Int. J. Multicriteria Decision Making, 33(23), 101-113. https://doi.org/10.1504/IJMCDM.2013.053727

Livi, A. D., \& Clifton, K. J. (2004). Issues and methods in capturing pedestrian behaviors, attitudes and perceptions: experiences with a community-based walkability survey. Transportation Research Board Annual Meeting, (April), 1-17.

Maghelal, P. K., \& Capp, C. J. (2011). Walkability: A Review of Existing Pedestrian Indices. URISA Journal, 23(2), 5-19.

Malczewski, J. (1999). GIS and Multicriteria Decision Analysis. In GIS, Remote Sensing, 
\& Cartography. New York: John Wiley \& Soons.

Malczewski, J. (2007). GIS-based multicriteria decision analysis: A survey of the literature. International Journal of Geographical Information Science, 20(7), 703726. https://doi.org/10.1080/13658810600661508

Malczewski, J., \& Rinner, C. (2015). Multicriteria Decision Analysis in Geographic Information Science. In Analysis methods. https://doi.org/10.1007/978-3-540$74757-4$

Marchi, G. De, Lucertini, G., \& Tsoukiàs, A. (2016). From Evidence-Based PolicyMaking to Policy Analytics. Annals of Operations Research, 236(1), 15-38.

Martin, W. E. E., Wise Bender, H., Shields, D. J. J., Bender, H. W., \& Shields, D. J. J. (2000). Stakeholder objectives for public lands: Rankings of forest management alternatives. Journal of Environmental Management, 58(1), 21-32.

Matti, S. (2004). The Individual or the Community: Towards a Common Understanding of Values . Luleå Sweden.

Meinard, Y. (2017). What is a legitimate conservation policy? Biological Conservation. https://doi.org/10.1016/j.biocon.2017.06.042

Moudon, A. V., \& Lee, C. (2003). Walking and Biking: An Evaluation of Environmental Audit Instruments. Americal Journal of Health Promotion, 18(1), 21-37. https://doi.org/10.4278/0890-1171-18.1.21

Moura, F., Cambra, P., \& Gonçalves, A. B. (2017). Measuring walkability for distinct pedestrian groups with a participatory assessment method: A case study in Lisbon. Landscape and Urban Planning, 157, 282-296. https://doi.org/10.1016/j.landurbplan.2016.07.002

Nussbaum, M. C. (2005). Capabilities as fundamental entitlements: Sen and social justice. In A. Kaufman (Ed.), Capabilities equality:Basic Issues and Problems (pp. 54-80). Routledge.

Oka, K., \& Koohsari, M. J. (2020). Walkable Neighborhoods The Link between Public, Health, Urban Design, and Transportation (K. Oka \& M. J. Koohsari, Eds.). Basel, Switzerland: MDPI.

Owen, N., Cerin, E., Leslie, E., duToit, L., Coffee, N., Frank, L. D., ... Sallis, J. F. (2007). Neighborhood Walkability and the Walking Behavior of Australian Adults. American Journal of Preventive Medicine, 33(5), 387-395. https://doi.org/10.1016/j.amepre.2007.07.025

Pawlak, Z. (1982). Rough sets. International Journal of Computer \& Information Sciences.

Pearce, D., Atkinson, G., \& Mourato, S. (2006). Cost-Benefit Analysis and the Environment: Recent developments. In Analysis (Vol. 115). Retrieved from http://www.journals.uchicago.edu/doi/abs/10.1086/426308

Peiravian, F., Derrible, S., \& Ijaz, F. (2014). Development and application of the Pedestrian Environment Index (PEI). Journal of Transport Geography, 39, 73-84. https://doi.org/10.1016/j.jtrangeo.2014.06.020

Pikora, T., Giles-Corti, B., Bull, F., Jamrozik, K., \& Donovan, R. (2003). Developing a framework for assessment of the environmental determinants of walking and cycling. Social Science \& Medicine, 56(8), 1693-1703. https://doi.org/http://doi.org/10.1016/S0277-9536(02)00163-6

Porta, S., \& Renne, J. L. (2005). Linking urban design to sustainability: formal indicators of social urban sustainability field research in Perth, Western Australia. URBAN 
DESIGN International, 10, 51-64. https://doi.org/10.1057/palgrave.udi.9000136

Qamar, U., \& Keane, P. J. A. (2012). Clustering Using Rough-Set Feature Selection . 2(6), 5915-5920.

Robeyns, I. (2017). Wellbeing, Freedom and Social Justice: The Capability Approach ReExamined. In Wellbeing, Freedom and Social Justice: The Capability Approach ReExamined. https://doi.org/10.11647/obp.0130

Robinson, J. (2001). Milestone report: A review of techniques to value environmental resources in coastal zones.

Rogers, S. H., Halstead, J. M., Gardner, K. H., \& Carlson, C. H. (2011). Examining Walkability and Social Capital as Indicators of Quality of Life at the Municipal and Neighborhood Scales. Applied Research in Quality of Life, 6(2), 201-213. https://doi.org/10.1007/s11482-010-9132-4

Rohrer, J., Pierce, J. R., \& Denison, A. (2004). Walkability and self-rated health in primary care patients. BMC Family Practice, 5. https://doi.org/10.1186/1471-2296$5-29$

Saelens, B. E., \& Handy, S. L. (2008). Built Environment Correlates of Walking: A Review. Medicine and Science in Sports and Exercise, 40(7 Suppl), S550-S566. https://doi.org/10.1249/MSS.0b013e31817c67a4

Saelens, B. E., Sallis, J. F., Black, J. B., \& Chen, D. (2003). Neighborhood-Based Differences in Physical Activity: An Environment Scale Evaluation. American Journal of Public Health, 93(9), 1552-1558. https://doi.org/10.2105/ajph.93.9.1552

Sen, A. (1995). Environmental Evaluation and Social Choice: Contingent Valuation and the Market Analogy. Japanese Economic Review, 46(1), 23-37.

Sen, A. (1999). Development as Freedom. In Oxford Press. New York: Anchor Book.

Sen, A. (2009). The Idea of Justice. Cambridge: Harvard University Press.

Simon, H. A. (1954). Some strategic considerations in the construction of social science models. In Simon H (ed), Models of bounded rationality: behavioural economics and business organization. Cambridge: MIT Press.

Simon, H. A. (1969). The sciences of the artificial. In Cambridge, MA. https://doi.org/10.1016/S0898-1221(97)82941-0

Siskos, J. (1983). Application de la méthodeUTAI à un problème de sélection de points de vente mettant en jeu des critères multiples. RAIRO. Recherche Opérationnelle, $17(2), 121-136$.

Siskos, J., \& Assimakopoulos, N. (1989). Multicriteria Highway Planning: a case study. Math. Comput. Modelling, 12(10/11), 1401-1410.

Siskos, J., Grigoroudis, E., \& Matsatsinis, N. F. (2005). UTA METHODS General philosophy. In Multiple Criteria Decision Analysis: State of the Art Surveys (pp. 297-334). New York: Springer.

Smeulders, B., Crama, Y., \& Spieksma, F. C. R. (2019). Revealed preference theory: An algorithmic outlook. European Journal of Operational Research, 272(3), 803-815. https://doi.org/10.1016/j.ejor.2018.04.026

Speck, J. (2018). Walkable City Rules. In Walkable City Rules. https://doi.org/10.5822/978-1-61091-899-2

Sundquist, K., Eriksson, U., Kawakami, N., Skog, L., Ohlsson, H., \& Arvidsson, D. (2011). Neighborhood walkability, physical activity, and walking behavior: The Swedish Neighborhood and Physical Activity (SNAP) study. Social Science and 
Medicine, 72(8), 1266-1273. https://doi.org/10.1016/j.socscimed.2011.03.004

Taleai, M., \& Taheri Amiri, E. (2017). Spatial multi-criteria and multi-scale evaluation of walkability potential at street segment level: A case study of tehran. Sustainable Cities and Society, 31, 37-50. https://doi.org/10.1016/j.scs.2017.02.011

Talen, E. (2002). Pedestrian Access as a Measure of Urban Quality. Planning Practice and Research, 17(3), 257-278. https://doi.org/10.1080/026974502200005634

Towne, S. D., Won, J., Lee, S., Ory, M. G., Forjuoh, S. N., Wang, S., \& Lee, C. (2016). Using Walk Score ${ }^{\mathrm{TM}}$ and Neighborhood Perceptions to Assess Walking Among Middle-Aged and Older Adults. Journal of Community Health, 41(5), 1-12. https://doi.org/10.1007/s10900-016-0180-z

Van Dyck, D., Cerin, E., Conway, T. L., De Bourdeaudhuij, I., Owen, N., Kerr, J., ... Sallis, J. F. (2013). Perceived neighborhood environmental attributes associated with adults' leisure-time physical activity: Findings from Belgium, Australia and the USA. Health and Place, 19(1), 59-68. https://doi.org/10.1016/j.healthplace.2012.09.017

von Winterfeldt, D., \& Edwards, W. (1986). Decision Analysis and Behavioural Research. Cambridge: Cambridge University Press.

Ward, J. H. (1963). Hierarchical grouping to optimize an objective function. Journal of the American Statistical Association, 58(301), 236-244.

Yameqani, A. S., \& Alesheikh, A. A. (2019). Predicting subjective measures of walkability index from objective measures using artificial neural networks. $\begin{array}{lllll}\text { Sustainable } \quad \text { Cities } & \text { and }\end{array}$ https://doi.org/https://doi.org/10.1016/j.scs.2019.101560

Zandieh, R., Flacke, J., Martinez, J., Jones, P., \& van Maarseveen, M. (2017). Do Inequalities in Neighborhood Walkability Drive Disparities in Older Adults' Outdoor Walking? International Journal of Environmental Research and Public Health, 14(7), 740. https://doi.org/10.3390/ijerph14070740

Zhou, H., He, S., Cai, Y., Wang, M., \& Su, S. (2019). Social inequalities in neighborhood visual walkability: Using Street View imagery and deep learning technologies to facilitate healthy city planning. Sustainable Cities and Society, 101605. https://doi.org/10.1016/j.scs.2019.101605 